\title{
Designing Hybrid Gifts
}

\section{Boriana Koleva}

Mixed Reality Lab, School of Computer Science, The University of Nottingham, Nottingham, UK, b.koleva@nottingham.ac.uk

\section{Jocelyn Spence}

Mixed Reality Lab, School of Computer Science, The University of Nottingham, Nottingham, UK, jocelyn.spence@nottingham.ac.uk

\section{Steve Benford}

Mixed Reality Lab, School of Computer Science, The University of Nottingham, Nottingham, UK, steve.benford@nottingham.ac.uk

\section{Hyosun Kwon}

School of Design and Creative Arts, Loughborough University, Loughborough, UK, h.kwon@lboro.ac.uk

\section{Holger Schnädelbach}

Mixed Reality Lab, School of Computer Science, The University of Nottingham, Nottingham, UK, holger.schnadelbach@hsaa.eu

\section{Emily Thorn}

Mixed Reality Lab, School of Computer Science, The University of Nottingham, Nottingham, UK, pszet@exmail.nottingham.ac.uk

\section{William Preston}

Mixed Reality Lab, School of Computer Science, The University of Nottingham, Nottingham, UK, william.preston@nottingham.ac.uk

\section{Adrian Hazzard}

Mixed Reality Lab, School of Computer Science, The University of Nottingham, Nottingham, UK, adrian.hazzard@nottingham.ac.uk

\section{Chris Greenhalgh}

Mixed Reality Lab, School of Computer Science, The University of Nottingham, Nottingham, UK, Chris.Greenhalgh@nottingham.ac.uk

Matt Adams

Blast Theory, Brighton, UK, matt@blasttheory.co.uk

Ju Row Farr

Blast Theory, Brighton, UK, ju@blasttheory.co.uk

Nick Tandavanitj

Blast Theory, Brighton, UK, nick@blasttheory.co.uk 


\title{
Alice Angus
}

Proboscis, London, UK, alice@proboscis.org.uk

Giles Lane

Proboscis, London, UK, giles@proboscis.org.uk

\begin{abstract}
Hybrid gifting combines physical artefacts and experiences with digital interactivity to generate new kinds of gifts. Our review details how gifting is a complex social phenomenon and how digital gifting is less engaging than physical gifting for both givers and receivers. Employing a Research Through Design approach, we developed a portfolio of four hybrid gifting experiences: an augmented advent calendar; edible music tracks; personalised museum tours; and a narrated city walk. Our reflection addresses three concepts: hybrid wrapping where physical gifts become wrapped in digital media and vice versa; the importance of effortful interactions that are visible and pleasurable; and the need to consider social obligation, including opportunities for acknowledgement and reciprocation, dealing with embarrassment, and recognising the distinction between giving and sharing. Our concepts provide guidance to practitioners who wish to design future gifting experiences while helping HCI researchers engage with the concept of gifting in a nuanced way.
\end{abstract}

\section{CCS CONCEPTS}

- Human-centered computing Mixed / augmented reality

\section{KEYWORDS}

Human-Computer Interaction, Gifting, Gift, Digital Gifting, Hybrid, Social Computing, Augmented Reality, Locative Media Audio, Tangible and Embedded Interaction, User Experience Design, Trajectories, Obligation, Embarrassment, Research Through Design

\section{INTRODUCTION}

Gifting is an ancient, familiar and important social activity for very many people. Gifts are routinely exchanged on birthdays, at births, weddings, anniversaries, as part of religious festivals, or as personal acts of friendship, romance and gratitude. Gifting is important economically, from gifting services in stores to corporate gifting. It is also widely discussed in the $\mathrm{HCI}$ and the wider research literature as we discuss below. As with many walks of life, digital technologies have become bound up with gifting, both in terms of the kinds of gifts that are given which may now take on digital forms such as music tracks, playlists or digital subscriptions, to enabling new ways of buying exchanging gifts via the Internet, including the routine inclusion of gifting options within online stores. This has fuelled a growing interest in gifting within HCI, including using gifting as a lens to help explain the sharing of personal messages and digital media as well as exploring the design of new digital gifts and gifting services. This paper focuses on the latter. Our primary interest lies in envisaging and ultimately helping people design new kinds of gift experience. Our particular focus is on hybrid gifting, the idea that physical and digital materials might combine to both extend the possibilities and flexibility of gifting physical items while also enriching the experience of digital gifting.

In what follows, we report the results of a Research Through Design process that explored through practice how one might design various hybrid gifting experiences. We present and analyse an annotated portfolio of gift experiences. Our reflections lead us to introduce to the new concept of 'hybrid wrapping' in which physical gift items may be wrapped in digital materials or vice versa. We discuss key aspects of hybrid wrapping, including designing trajectories through wrapping and unwrapping, effortful interactions, and managing social obligation, relating each to the wider HCI literature. Our intention is to expand the repertoire of techniques available to the designers of a wide range of everyday gifting experiences, from the gifting of 
subscriptions and playlists on digital streaming services, to enriching the gifting options currently offered by online stores, to being able to wrap traditional physical items with personal messages that leave behind valuable memories on social media. At the same time, we also intend our exploration to shed new light on HCI's wider engagement with gifting as a highly nuanced social phenomenon.

\section{INSIGHTS FROM THE GIFT-GIVING LITERATURE}

We consider related work from three perspectives. First, we briefly review the extensive literature from the social sciences, and especially from anthropology, on gifting as a social phenomenon. Second, we turn to HCI's engagement with gifting thus far, both as a lens to understand social interaction with digital technologies and also as a distinct form of interactive user experience to be designed. Finally, we consider previous discussions of hybridity within HCI that inform our ideas of hybrid gifting and wrapping.

\subsection{Gift Exchange from Socio-anthropological Perspective}

Gifting is a near-universal sphere of activity whose fundamental structures are often well understood, if implicitly, among members of a given society. However, formal research into gift-exchange processes only took off in the 1920s with the work of Bronislaw Malinowski (1922) and Marcel Mauss (1925), both of whom studied non-Western peoples from the perspectives of anthropology and sociology (Melanesia for Malinowski and Melanesia, Polynesia, and the Pacific Northwest for Mauss). Both focused on the concept of reciprocity, as seen in the social obligations met or incurred when a gift is given, and therefore both conceived of gift-giving as a fundamental part of social systems. According to Markus Giesler in his overview of the gifting literature, "Gift systems are so important because they are systems of social solidarity (Komter 2005) that help shatter the ego bonds of the alienated self (Hyde 1983) and establish and maintain the essential vitality, viability, and identity of the society in which they are embedded (Cheal 1988)." In what follows, we will address various facets of what makes gifting such a distinctive and powerful social process.

\subsubsection{Process}

Gift exchange is generally seen as a distinctive process involving multiple stages. A few researchers have suggested models of gifting process. Mauss' three types of obligation have been a pre-eminent theoretical model to be found in the gifting literature. The three obligations: to give, to receive, and to reciprocate have been the central concern in the bodies of work spanning sociology (Komter 2007), economics (Banks 1979) and anthropology (Sherry 1983). In the context of consumer marketing, Banks (1979) articulated a 4-stage model of interpersonal behaviours in the exchange of consumer goods comprising purchase, interaction/exchange, consumption, and communication/feedback. Sherry (1983) illustrated gifting by using a 3-stage model: gestation, involving motives and search; prestation, where exchange and response happens; and reformulation, leading to disposition of the gift and reciprocation. Sherry's model describes a broad spectrum of the gifting process in detail and is widely cited by scholars in adjacent disciplines. Nonetheless, some have argued that its many variables and concepts add complexity that may become a limitation for analytic studies (Sunwolf 2006).

\subsubsection{Effort}

Whichever model one adopts to model the process of gift exchange, one might inevitably start the journey from giving or planning to give. Gifting commences its course by the giver's willingness to sacrifice his or her monetary, labour, and temporal resources (Cheal 1987; Wooten, 2000) in an effort to make or procure a gift. Effort in searching, purchasing, or crafting may be expended in the preparation stage to transform virtually anything into a gift (Komter 2007). Givers may invest considerable emotional effort, particularly in the selection of the gift (Davies et al 2010). Cheal (1987) identified that the sacrifice of the gift giver's time or labour may add value to the gift. The time spent in searching for and purchasing the gift symbolises the giver's effort invested in maintenance of the relationship, without being explicit (Pandya and Venkatesh 1992, p.153). Also, Larsen and Watson (2001) suggested that the giver's sacrifice can be construed in terms of two types of cost: financial cost and psychic cost. The former denotes a monetary or economic value of the gift, while the latter can be viewed as an investment of time and emotional effort expended in the selection 
of the gift. The sacrifice of time and effort is often maximised in romantic relationships (Belk and Coon 1993). The gift-giver seeks to bring happiness to the lover by sacrificing their own pleasure in favour of the pleasure of the partner, as opposed to the economic exchange model (ibid).

The evident importance of effort to gift giving can be related to HCI's interest in effortful interfaces. Previous HCI research has argued that effortful interfaces might be useful for learning (Cockburn et al. 2007) or increasing the hedonic pleasure of user experiences (Frolich and Murphy 1999). Ryan Kelly and colleagues (2017) focus on the effort that a giver goes to as key to a sense of meaningfulness in personal communications, and Riche et al. (2010) found in their study that older adults sometimes perceived messages sent via low-effort devices as being less valuable and diminishing the value of the relationship.

\subsubsection{Wrapping}

A near-universal method of showing one's effort is by wrapping a gift item. Wrapping is one of the key rituals in gift exchange that symbolises the gift. Givers may select a wrapping paper, customise packaging, and draw or write a message to express care and affection to the recipient. The design and style of the wrapping may vary widely based on its cultural origin. Hendry (1995) describes how various types of wrappings are deliberately designed and coordinated with different occasions of gift-giving in Japan. By wrapping a gift, givers are adding layers of meaning and purposefulness to the gift in its uncovered form. Concern and effort put into the wrapping highlights the social agreement that it is not the item but the manner of giving a gift that matters (Cheal, 1988). The wrapping can also take a non-physical form when the gift item is intangible or experiential. Shared experience gifts are perceived as useful vehicles for showing the giver's sacrifice of time to the recipient (Clarke, 2007). Experiences can be uniquely customised by expending the giver's effort in wrapping an event in a way that is uniquely tailored to the recipient (Sherry, 1983). Wrapping also enables surprise (Hendry, 1993), which is often an essential ingredient of gift giving (Ruffle 1999), particularly in Western societies, represented by the norm of the 'perfect gift' (Belk 1996).

\subsubsection{Obligation and anxiety}

While the motivation to sacrifice one's labour in gift-giving is nearly always to achieve the positive, the nature of gifting as a powerful social transaction can give rise to strong feelings of obligation, suspense and even anxiety. The need to be seen to invest effort into the gift is one form of obligation that dominates the giver's motivation: to avoid giving an inappropriate gift. Anticipation of the recipient's reaction may give rise to feelings of anxiety in the giver. Anxiety in gift exchange has been widely discussed in the literature about gift selection (Otnes, Kim, and Lowrey 1992), presentation (McGrath et al. 1993), and disposition (Sherry et al. 1992). Anxiety increases in situations where there are no guidelines for gift selection, for example, when there is a lack of information about the recipient's preferences. Moreover, when a gift is made in public, for example at a gifting occasion such as a birthday party, and so subject to the scrutiny of others, both giver and recipient's anxiety increases since the situation challenges the appropriateness of the gift given, the manner of exchange, and the recipient's reaction (Davies, G. et al. 2010). Inappropriate gifts cause embarrassment, threaten social ties, and leave a poor impression (Sherry et al. 1993). Moreover, the recipient's expectation imposed upon the giver becomes a possible source of anxiety when it is unattainable (ibid). Surprise gifts can be a source of social anxiety, when givers 'are motivated to make desired impressions but are doubtful of success' (Wooten 2000, p. 85).

\subsubsection{Reciprocity}

Obligation arises not only in giving, but also in receiving and repaying (Belk, 1976). Obligation to accept a gift may spark the tension to reciprocate, which is a significant cause of stress and anxiety (Larsen and Watson 2001; Wooten 2000). Literature in the lineage of Mauss's model concerns reciprocity as a powerful motivation that drives gifting as a self-perpetuating system (Komter, 2007; Levi-Strauss, 1996). Looking at the very concept of gifts and the material or psychological benefits that arise through the act of gifting, Jacques Derrida (1992) argues against the idea of reciprocity as part of a true gift-giving process. He claims that gifts can only be gifts when they are not perceived as such: the moment the recipient understands that he or she has received a gift, a sense of obligation comes with it, making traditional or overt gift-giving experiences mere mechanisms for generating indebtedness, a duty to reciprocate. Another challenge to the 
centrality of reciprocity in the concept of gift exchange comes from Annette B. Weiner's (1992) feminist critique of Mauss' seminal work mentioned above. Drawing on her own decades of experience with many of the same non-Western groups that Mauss studied as well as others and explicitly extrapolating her findings to contemporary Western gift exchange, Weiner argues that, rather than serving to generate obligation and reciprocation, the true value of a gift may lie in its connection to the person who owned it - the giver - so that gifts serve to 'retain for the future, memories, either fabricated or not, of the past', a concept that she refers to as 'inalienability'.

\subsection{Gifting from an $\mathrm{HCl}$ perspective}

There is an extensive body of work focusing on gifting in online communities (e.g. McGee and Skågeby 2004; Salovaara 2008; Skågeby 2010; Bradford et al 2012; Watts and Shmargad 2015, Karyda et al 2018). HCI's engagement with online and digital gifting has encompassed two distinct perspectives.

\subsubsection{Understanding digital media practices}

The digital facilitation or replacement of physical gifting processes has posed a series of challenges to the perception of what a digital gift entails and how valuable it is.

The difficulty of pinning down what a giver or receiver perceives as a real gift in a digital context is in many ways tied to the fact that digital norms have become embedded in everyday life practices far more quickly and strongly than the concept of a digital gift has - much less a hybrid gift. Some HCI researchers have uncovered gifting simply as a finding in work aiming to explore emerging digital practices. For example, some interview respondents stated that a playlist needed to be personalised with photos or text to make it feel like a gift (Odom et al 2011 p. 1496); another bought and engraved an iPod into which he uploaded carefully chosen digital music tracks in order to make the music feel like a gift (Leong \& Wright 2013); and 8\% of the designs studied by Marc Hassenzahl and colleagues (2012) for maintaining intimate long-distance relationships using digital technologies aimed to support those relationships via gift-giving. 'Reflection, effort and appreciation, thoughtfulness and similarity, [and] symbolic communication' were the key design elements of these (Hassenzahl et al 2012 p. 5).

As it is so ubiquitous and well-researched in other disciplines, gifting has also provided HCI researchers with a theoretical lens for understanding social practices surrounding the sharing and ownership of digital media. Taylor and Harper (2002) argued that the rituals surrounding the exchange of text messages by teenagers could be viewed as a form of gifting. Extending this to public communication, Schwarz (2010) argued that public comments or tags on social networking sites such as Facebook involve a sense of 'gift receiving' as they draw public recognition. Yang et al. (2011) viewed virtual currency systems in Chinese online communities through the lens of guanxi, a tradition that fosters social ties based on gift exchange. Moreover, researchers have explored that personalized music files, albums and playlists were exchanged among teenagers as a form of gift (Odom, et al. 2011). Brown and Sellen (2006) observed that while digital music files were personally valued when exchanged as gifts, they were less preferred form of music than CDs and vinyl. Incorporating tangible materials to convey digital gifts has also been explored to enhance social communication using media as diverse as postcards (Kelly 2012) and food (Wei 2014). Other researchers (Janice et al. 2012; Golsteijn et al. 2012; Odom et al. 2010) also have explained how immaterial - i.e., digital - things may gain meaning and become cherished over time. Collectively, this body of work reveals how emergent practices involving the sharing of digital media online can often resemble gifting.

However, this is not to say that gifting and sharing are one and the same. Online gifting is easily conflated with sharing, primarily because the mechanisms of exchange are essentially the same. This situation makes it easy to perceive properties of gifting in transactions that could otherwise be understood as sharing and vice versa (see e.g. Ripeanu 2006, Salovaara 2008, Antal \& Richebé 2009). However, Spence (2019) has recently 
drawn on Weiner's concept of inalienability to argue that gifting can be distinguished from sharing due to the importance of associations with the giver, personalisation and effort. The concept of inalienability applied to gifting in general and gifts that have an intangible digital component in particular is helpful in pinpointing those elements of a gift experience that connect the gift object to the gift-giver, including the effort to which the giver went in order to create or procure the gift. This also helps us pursue ways in which that effort can be tailored to the desires of the receiver, including the seemingly paradoxical finding that certain situations are best served by gifts that highlight the giver's preferences over the receiver's (Paolacci et al 2015).

The very fact that gifting is so deeply embedded in everyday life means that the adoption of emerging norms of digital behaviour can lead to mismatches between expectations and real-world experiences of digitally enabled gifting. As noted above (Brown \& Sellen 2006, Odom et al 2011, Leong \& Wright 2013), some respondents found that music playlists could make good gifts, but especially (or only) if they were given a physicalised or personalised component. Obligations to reciprocate emerge as sometimes insurmountable obstacles in a design for online communication framed as gifting (Salovaara 2008); the need to give for the giver's own sake in an online context where everything is freely shared becomes apparent (McGee \& Skågeby 2004); anxieties around any kind of traditional gift-giving (see e.g. Sherry et al 1993, Wooten 2000) are exacerbated as the number of online witnesses to the gifting increases (Watts \& Shmargad 2015).

Kwon et al. (2017-a) explicitly compared people's experiences of physical and digital gifting. They began by synthesising a model of gifting from the wider sociological literature that broke the gifting experience down into the five key stages of: preparation, exchange, reveal, use, and reflection. They then invited study participants to recall and reflect upon examples of physical and digital gifts that they had both given and received previously. Participants also rated their level of engagement with each stage of the gifting experience. Their results showed that both the giving and receiving of digital gifts was felt to be less engaging than that of physical gifts at every stage of the process, and especially at the reveal stage for givers and also the reflection stage for recipients.

\subsubsection{Designing new gifting experiences}

Other HCI researchers have turned to gifting to directly inform the design of new user experiences, explicitly seeking to create new gifting services. Fosh et al. (2014) explored how visitors to a museum could compile personal tours for others by selecting relevant exhibits from the museum and then combining them with digital media including their own interpretations, explanations of significance, instructions for how to engage with them, and music to accompany them. Their initial study involving romantic couples showed how this approach might help address museum goals of delivering more personalised and social visiting experiences and encouraging visitors to interpret exhibitions in new ways. They also revealed how the approach introduced some risk of embarrassment and social awkwardness when gifts or interpretations were ill judged by either party - especially as the receiver undertook the tour in the presence of the giver, who watched them throughout. Their subsequent redesign and study extended the approach to groups of friends and family, with each member choosing and interpreting one exhibit for each other as part of a novel peer-gifting service (Fosh et al 2016). Frohlich and Murphy (2000) studied how stories become attached to souvenirs to create personalized memorabilia that can then be shared as gifts. Such experiential gifts were seen to be a useful way of supporting intimate relationships, as both giver and recipient are able to share memories and reflect upon these later. More recent work has explored gifting-based interaction design as a means of engaging children with nature (Silver and Rosenbaum 2010) Others have recognised food as a medium for social communication and gift-giving (Barden et al., 2012; Grimes and Harper, 2008). One might for example consider preparing gifts (e.g. messages) by using food as a vessel that delivers a digital payload (Wei et al., 2014).

Our paper sits in this latter camp. We explicitly tackle the question of how we might design novel forms of gifting experience that incorporate digital technologies. In so doing, we directly build on several of the ideas 
from previous work including the potential for incorporating digital music into gifts, creating personalised visiting experiences as gifts, and combining food and other physical materials with digital media to create new kinds of 'hybrid gift'.

\subsection{Hybridity}

Before turning to our approach and portfolio, we first briefly review one more area of the literature that is important to our paper, the idea of physical-digital hybridity. For several decades now, HCI researchers have explored diverse approaches to bringing computing into the physical world including Ubiquitous Computing (Weiser 1991), Tangible and Embedded Interfaces (Ishii and Ullmer 1997), and Mixed Reality (Milgram and Kishino 1994). The resulting interfaces that mix physical and digital elements of interaction in different ways have often been referred to as being 'hybrid'. HCI has broadly explored the concept of hybridity at the three levels of: materials, artefacts and experiences. Combinations of physical and digital materials might lead to new kinds of transmaterials (Bronwell, 2006), composite materials (Vallgarda and Redstrom, 2007) or textures (Robles and Wirberg, 2010). Hybrid artefacts might extend physical things with layers of digital information that enhance their provenance, utility or personal meaning (Benford et al, 2018). While hybrid experiences may combine physical and virtual settings to realise extended theatrical performances or museum visits (Benford and Gianacchi, 2011). Hybrid craft has also emerged as a distinct area of HCI research that emphasizes the merging of digital and non-digital material, artefacts and processes through the practice of crafting (Buechley et al 2012, Golsteijn et al 2014, Devendorf and Rosner, 2017, Benford et al 2017). One common approach to delivering hybridity that is important to this paper is that of layering in which materials, artefacts or experiences are composed from physical and digital layers as this directly speaks to our interest in wrapping. Technologies such as augmented reality and locative media appear to overlay digital layers on physical artefacts or settings. Interactive museum guides can be viewed as overlaying digital media onto the physical collection and setting of a museum. In contrast, the technologies of tangible and embedded computing might be seen as layering the physical on top of the digital.

\section{A RESEARCH THROUGH DESIGN APPROACH}

Our research sits under the broad umbrella of Research Through Design, following a practice-led approach in which we formed transdisciplinary teams, including artists and makers, to create and reflect across a portfolio of speculative designs of hybrid gifting experiences. The nature of Research Through Design has been somewhat contested with HCI. Zimmerman et al (2007), building on the work of Frayling (Frayling, 2003), focus on tackling "wicked problems" that, due the complex needs of diverse stakeholders, cannot readily be addressed by the "reductionist approaches of science and engineering". They stress the designer's role in "trying to make the right thing", that the resulting design artefacts provide "concrete embodiments of theory and technical opportunities", and also call for a greater clarity and consistency of evaluation through the four criteria of process, invention, relevance and extensibility. Gaver (2012) adopts a more relaxed view, celebrating the diversity of approaches as providing opportunities for creative and playful engagements with the world and advising the community to be "wary of impulses towards convergence and standardisation and instead, take pride in its aptitude for exploring and speculating". With regards to 'evaluation', he proposes that the outcomes might usefully take the form of portfolios of artefacts and systems that are annotated with "topical, procedural, pragmatic or conceptual" insights, from reflections on use in the field to conceptual frameworks.

Our interpretation of Research Through Design in this paper leans towards the exploratory, speculative and generative view espoused by Gaver. HCI and interaction design researchers are still at the early stages of exploring what digital or hybrid gifting might mean, we believe the design space of digital or hybrid gifting to currently be open territory that should be approached with an open mind. We are therefore not so much concerned here with tackling an identified wicked problem as we are with speculating on the broad potential future digitally-enabled gifting experiences. We therefore report an exploratory research process in which we created speculative and contrasting examples of hybrid gifting experiences. We present these in the form 
of an annotated portfolio, around which we have built an argument for hybrid gifting as an emerging and worthwhile 'domain of design' (Gaver 2012 p. 944).

Our portfolio emerged from several years of research in which we explored the design of hybrid gifting in different contexts and under the aegis of different funded projects, and comprises four examples: an augmented advent calendar, edible music tracks, personalised museum tours and musical city walks. Each of these explores the giving and receiving of a different kind of gift within a particular context. We did not set out with all of the designs or contexts already in mind as if addressing a known hypothesis, but charted out the territory of what we increasingly came to see as a new form of 'hybrid' gifting. The individual designs along with evaluative studies have been published previously so that the contribution of this paper is to consider them as a portfolio and reflect on how collectively, they shape the personally and socially meaningful rituals surrounding gifting, especially when the things being gifted have a significant digital component. We begin by briefly summarising each of the four designs before then reflecting on cross-cutting themes.

\section{A PORTFOLIO OF HYBRID GIFT EXPERIENCES}

Our case studies explore the idea of hybrid gifting in very different contexts: two in which digital artefacts are gifted by being tethered to physical objects, and two in which the digital artefact is gifted by being embedded in a personalised, multisensory physical experience. They can be summed up as follows: an Augmented Advent Calendar that givers personalise with digital content for receivers; Edible Music Tracks where digital music tracks are wrapped in food; the Museum GIFT App in which people gift personalised museum tours to others and The Rough Mile, a locative media experience in which both givers and receivers undertake a city walk in order to inspire, select and ultimately listen to personal music playlists. Although distinct in many ways, all four examples reveal common challenges with implications for design, gifting research, and a broader understanding of how digital and hybrid objects can influence personal relationships. This portfolio of designs emerged through an exploratory, rather than a pre-planned, RTD process in which new ideas for gifting experiences were inspired and informed by previous ones, often in parallel. To give some sense of the overall timeline as context, our initial interest in gifting arose through Lesley Fosh's PhD work (2014) which involved low-fi prototyping and studies of gifting as a novel approach to embedding personalisation, interpretation and social coherence into museum visits. In parallel, Kwon's PhD research into ephemeral media (2015) alighted on the idea of wrapping digital media in delicate physical materials to create edible musical gifts and also conducted the (2017-a, b) study of physical versus digital gifting discussed above. These two exploratory PhDs then fed into two attempts to create and deploy gift products at greater scale, first the Christmas with Artcodes advent calendar (2018) and finally Blast Theory's gift app (2019) which neatly rounds off the story by extending and fully implementing Fosh's original idea five years after its initial conception. Throughout this time, ideas of physical-digital layering, wrapping and residues were being discussed and refined and elements of them can be found in the previous publications. However, it was writing this paper that involved reflecting back across all four examples and synthesising previous discussions into a more complete framework that combines ideas of physical-digital layering and the fivestage process of gifting as set out below.

\subsection{Christmas with Artcodes - digitally personalising a physical gift}

As part of a transdisciplinary collaboration between MRL and creative studio Proboscis, artists Alice Angus and Giles Lane were commissioned to research and design a paper based activity to investigate sharing and gifting with the Artcodes pattern recognition system. Proboscis drew on past work into tangible souvenirs, public goods, public authoring, "artefacts that represent those things we most value about our communities" and "physical things that act as triggers for intuitive reflection" (Roussos et al, 2014). They considered how social rituals and behaviours around gifting and sharing occur at Christmas (the intended time for the project deliverable to be released). Through a process of investigation through making, they developed a physical Advent Calendar that people could use in several ways to author and share digital stories. The 
calendar is a suitable probe for exploring the question of how hybrid products can be personalised and gifted to others. Traditional physical advent calendars are commonplace and widely consumed items, while online digital calendars have grown in popularity over recent years, which motivated us to explore some form of hybrid product that could bring the two together. We hoped that, as a long established ritual at Christmas, the calendar would be sufficiently captivating and fun to attract people to easily engage on a first encounter. At the same time, we also hoped it might lead them into deeper engagement over a period of a month or so. The design of the calendar and a study of how it was experienced over a Christmas season have previously been published in (Benford et al, 2018). The following summarises the most salient points for this current paper. Physically, the advent calendar took the form of the cardboard structure shown in Figures 1 and 2 (illustrated and designed by A.Angus). An introduction and instructions were provided on the outside of two cardboard flaps (with links to a website for further instructions), which opened out to reveal a Christmas scene that spread over two A3 pages. The calendar came with 24 stickers (Figure 3) that could be placed in any order under its 24 doors. The idea behind using stickers was to offer a simple entry-level step to customization while also allowing the calendar to be assembled at a time of its owner's choosing: perhaps in one or more sessions prior to the Advent season, or a day at a time during the 24 days leading up to Christmas, or some combination of these 1 .

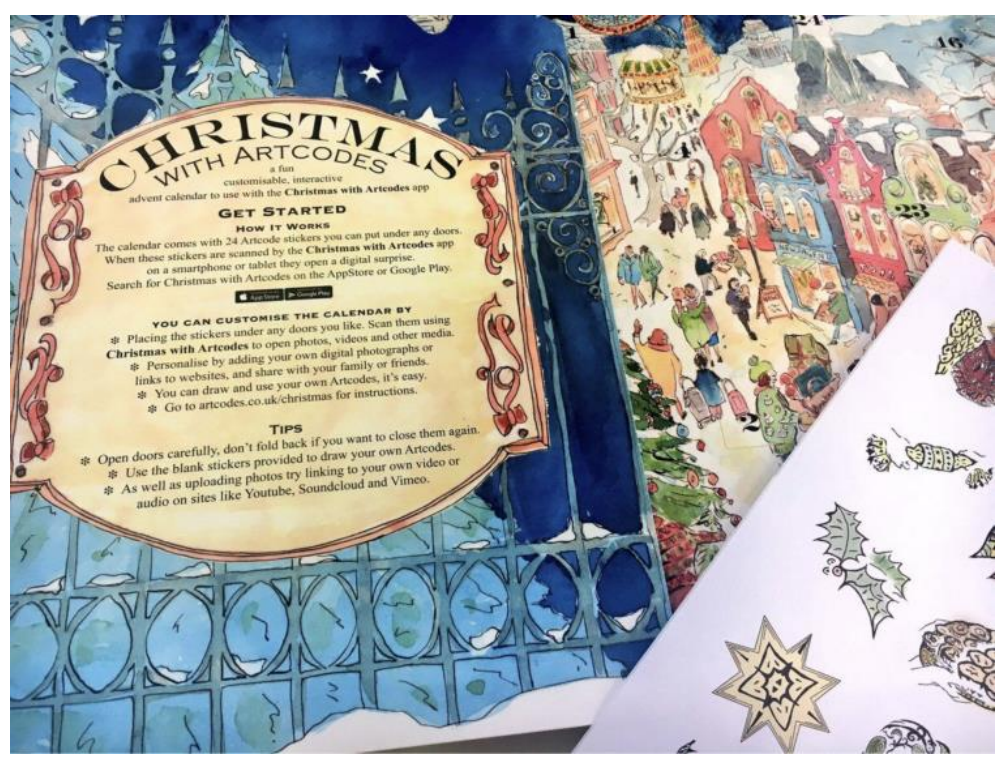

Figure 1. The Augmented Advent Calendar on opening the package 


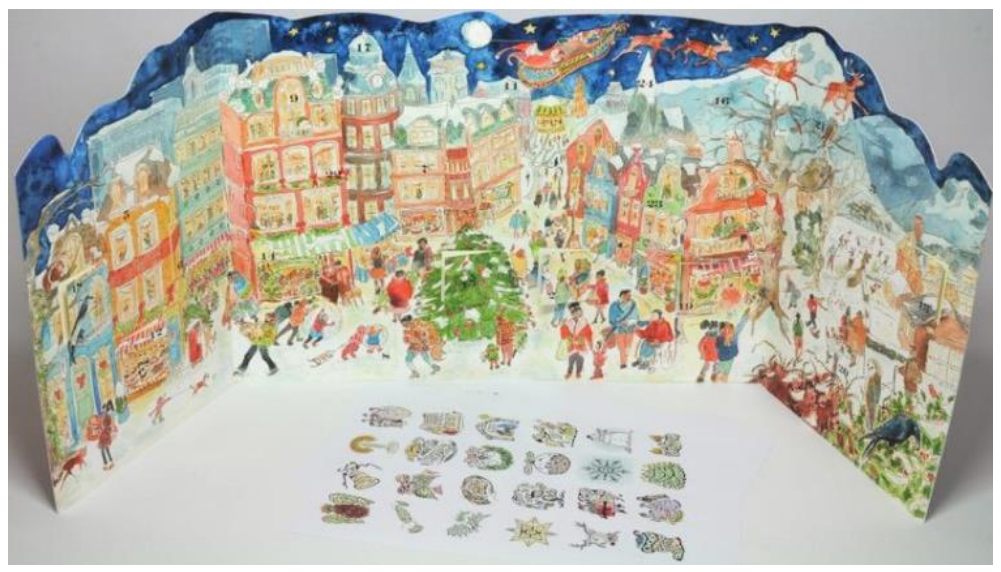

Figure 2. The Augmented Advent Calendar opened up (Illustration \& design A.Angus 2016)

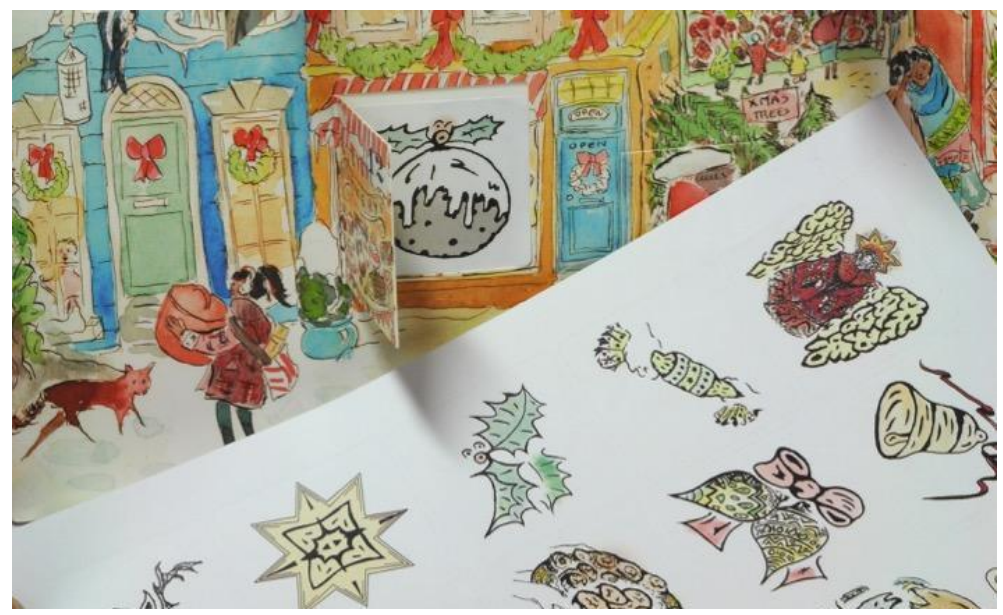

Figure 3. Stickers and doors (Illustration \& design A.Angus 2016) 

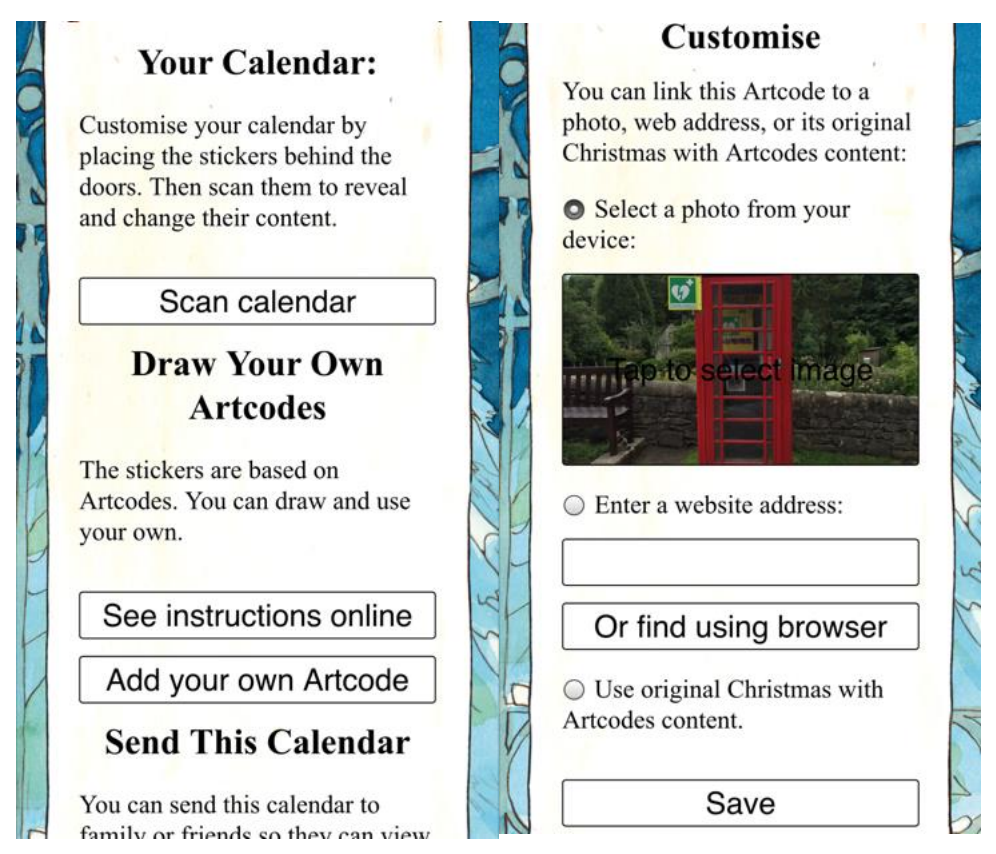

Figure 4. The Augmented Advent Calendar app for personalising the gift (Illustration \& design A.Angus 2016)

Each sticker was a computer-recognisable visual marker realised using the Artcodes (Benford et al, 2017) implementation of Costanza and Huang's (2009) D-Touch technique. Scanning it using the accompanying mobile app triggered the display of associated digital content, either a photograph or a webpage. The Artcodes technology also enables people to draw their own markers and so sheets of blank stickers, as well as links to instructions and tutorials, were provided so that calendar owners could learn to draw their own designs, rather than use our default ones, as a further act of customization.

The calendar came with a bespoke app (Figure 4), available via Google Play and iTunes, for scanning the stickers. By default, this connected the user to a series of Christmas themed and freely available web pages that we had curated from the Internet including: links to Christmas songs, animations, classic movie clips, jokes, games, puzzles and suggestions for seasonal cooking and crafting activities. Scanning a sticker also revealed an option for the user to customize its content by providing a URL or uploading a photo from the phone. The resulting customizations could be saved as a local version of the calendar (a layer of links to content) called 'My Calendar' and this could then be shared with other people as a link embedded into email, text and social media. Incoming calendar layers from other people were added to a local list of available calendars and could also be re-shared with others. In this way, calendar owners could customize its digital content, effectively wrapping the calendar in their own layers of media, and give it to others. We also provided a web-based editor to ease the task of creating and sharing entire layers.

The previously published study drew on observations from workshops and craft sessions, interviews with givers and receivers of personalised layers of content, and also application log data that captured patterns of use by several hundred calendar owners, to paint a picture of how the calendar was used. A key funding of the study was that calendar users engaged in various forms of customisation, both digital with people making layers for others, but also physical in which they drew and arranged stickers and in some cases even treated the calendar as a kind of craft kit for making other kinds of Christmas-themed products. A further key finding was how the calendar supported families and groups of friends in making gifts based on the sharing of personally meaningful memories, photos and jokes. The research also revealed that participants valued sharing calendars with remote family and friends who they could not physically be with at Christmas pointing to a much richer and deeper potential for hybrid digital/physical products to facilitate emotionally meaningful connections between geographically remote people as a form of gifting in and of itself. 


\subsection{Edible Music Tracks - wrapping digital music in food}

Our second case study brings together digital music and food, both of which enjoy strong associations with gifting. Music tracks are a common source of digital gifts as reported in (Kwon et al., 2017-a). Indeed, researchers have previously argued that music streaming services have transformed music distribution into being a gift economy (Leyshon 2014). Food has a rich cultural, historical background that engenders a variety of social practices in preparing, sharing, exchanging and eating - including gifting. HCI has recognized the potential of food to create edible interfaces. For example, the flavour of the food has been explored in enhancing playful experiences (Murer et al., 2013) or togetherness in dining with telepresent others (Barden et al., 2012). Human-food interaction has been proposed as a prospective design space in HCI (Grimes and Harper, 2008) that focuses on positive and celebratory aspects of food in our social, cultural life from multiple dimensions, including eating, sharing and gifting. This inspired us to explore how food and specifically edible interfaces might be combined with digital music to create unusual gifting experiences.

Our response was to imagine food as being the wrapping for a digital gift, by which we meant that a digital gift such as a music track could be associated with an item of food that, in the moment of eating, would reveal the enclosed digital (musical) gift and convey a oral-aural user experience. The digital track would then remain in the receiver's collection (e.g. mobile app) that can be reheard and shared afterwards. By incorporating food as a wrapping material, we reintroduced unwrapping interaction that spontaneously arise in the course of dining or eating. Thus, this case study shows how we can reinstate the reveal stage in digital gifting through the gastronomic tangible interaction. Moreover, by choosing a food item that demands immediate consumption, the exchange situation imposes an obligation to receive and respond at the same time. This might either heightens excitement in the course of receiving the gift or can potentially cause awkwardness or discomfort to the receiver.

We prepared a selection of delicate desserts using a spherification-like technique. It is a food production technique that was first patented (U.S. 2403547) in Britain in 1942 by William Peschardt, a food scientist working for Unilever. We used a widely available recipe to create the dessert that demands delicate handling in both creating and eating. The dessert can be created by submerging a juice or flavoured liquid with calcium content in a bath of sodium alginate. A reaction between the food substances eventually generates a spherical shaped liquid that enwrapped by an ultra-thin membrane. It appears to be fragile and delicate that would break even by very light touch. Once the dessert is poked by a cutlery, the inner liquid pops out and become available to be dined (shown in Figure 5). A key aim of using the spherified liquid dessert was to engender a sense of precariousness when unwrapping the digital gift, both visually and tangibly through the 'pop' sensation that would demand careful and prudent actions by the receiver. The dessert is totally edible, which can be coloured and flavoured. From the outset, a giver can devise the flavour of the dessert to match with the type of the music track or sync the length of the music with the approximate duration of eating the dessert to offer an impression that the music track is edible.

We constructed an interface for interacting with the food in the form of an augmented dining table (Figure 6), comprising a table with a web-cam mounted underneath its surface, and a transparent plate. When the dessert blob is placed on the plate the camera identifies the colour of the blob. Once the receiver breaks the blob, the camera detects its changed state by comparing the size of the blob. Then a digital gift seamlessly being presented to the recipient, for example, a music track is played. At the end of the dining experience, the physical wrapper (dessert blob) is no longer present, but the digital gift remains in the receiver's collection.

2 http://www.molecularrecipes.com/spherification-class/reverse-spherification/ 

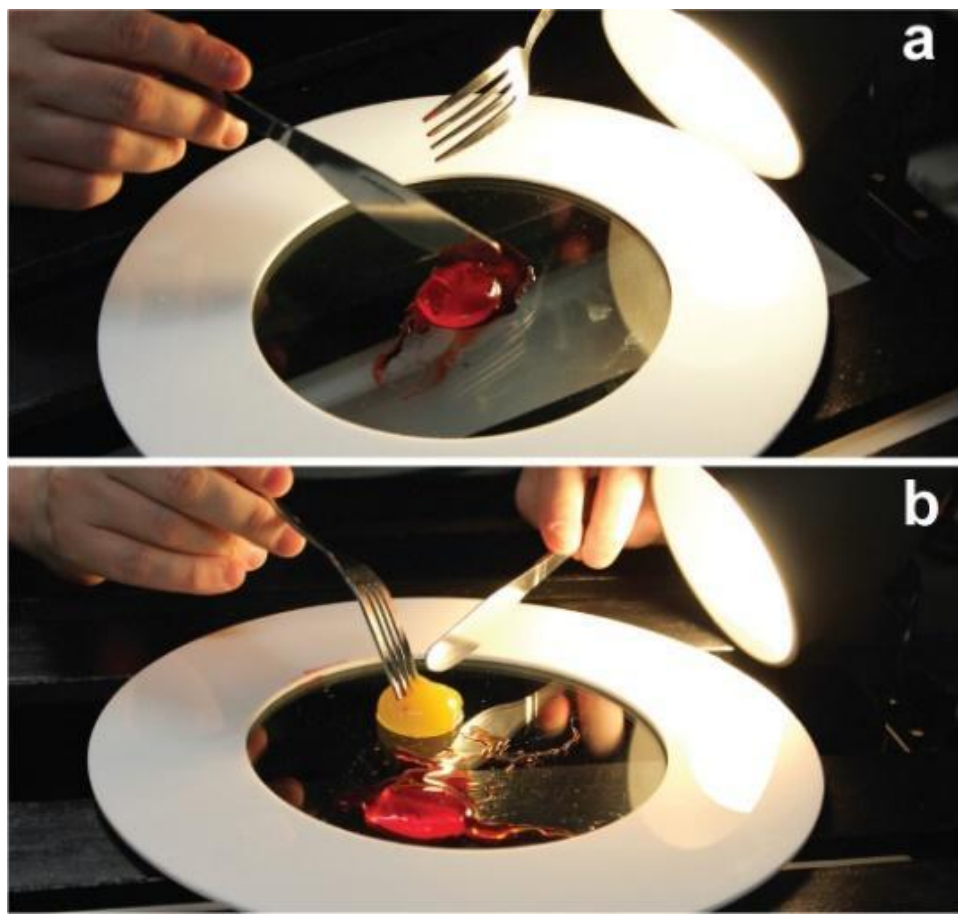

Figure 5. Both a and b illustrate a recipient interacting with the spherified desserts.

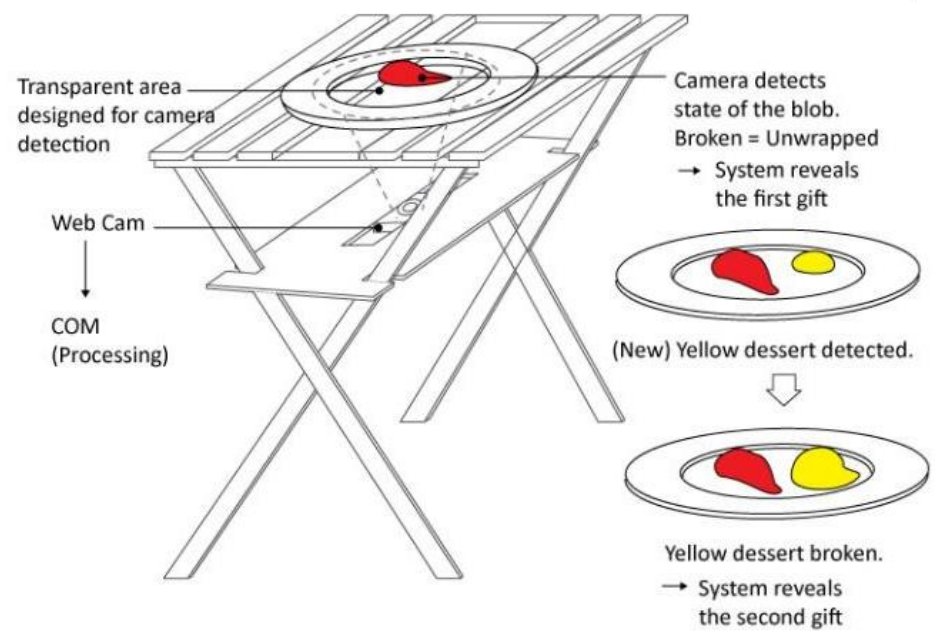

Figure 6. The augmented dining table and illustration of how the dessert wrapping is being unwrapped.

We conducted a design workshop (Kwon, 2017-b) to capture how potential users might make sense of the 'unwrapping' stage in digital gift exchange. We recruited eleven people who had taken part in our interview study of digital gifting reported in (Kwon et al., 2017-a) dividing them into three groups (groups of size 4, 3, and 4) according to their availability, with each group attending for a 90 minute session on a different day. We prepared two digital gifts for each participant, a music track and a gift voucher (£15 worth of Amazon voucher for a compensation). The music was played at an instance of the first unwrapping interaction and at the second unwrapping; the voucher was sent to the participants' inbox via email, which they could check with their mobile phones on site. The two gifts were configured differently: the music track plays only once 
during dining, embedding an idea of ephemerality (Kwon et al., 2015) to the digital gift; while the voucher could be kept and consumed later, i.e. embedding the notion that many gifts become one's keepsake, albeit temporarily. Followed by the experience of these two different configurations, a hands-on design session was held where participants were encouraged to explore their own ideas of physical wrappings for digital gifts, with a range of crafting materials provided. The workshop was then wrapped up with a debriefing session in which each participant reflected on the prototypes and expressed their ideas. All the sessions had been video recorded with audio.

The edible music track was appreciated among the workshop participants, particularly, in veiling the genuine digital gift to enhance the tension and curiosity experienced when unwrapping it. From the previous study (Kwon et al., 2017-a), email or a messaging application was identified as a typical method of exchanging digital gifts. A notable pitfall of the email and message was that the givers often had to inform, in advance, the recipient to check their inbox to make sure the recipients do not miss it. This extra notification step and non-synchronic exchange were seen to be diminishing the excitement in both giving and receiving the digital gift. But, by removing the unavoidable preview and notification, the edible music tracks would complement the weakness of the digital gifting experience. Moreover, food was deemed an effective interactive material for the wrapping with the series of actions involved in receiving, unwrapping and consuming. Seamlessness in opening - by using cutleries - and receiving the gift in the course of dining shaped a well-formed gifting experience. Also, a combination of colour, aroma, and flavour renders a multi-sensory experience. Furthermore, due to multiple participants being present at the workshop, the experience of receiving the edible music gift aroused a sense of social dinning. Later in the debriefing session, some participants had noted that there was a light obligation to respond 'nicely' when they received and unwrapped the edible gift as other participants were focusing on them.

In addition to its function as a passive encloser of a digital gift, deformable food material was envisioned to be used as an interactive cue for opening the gift. Figure 7 shows an example suggested by a participant in the workshop. A particular shape or pattern can be set up in advance by the giver, like a passcode, and the digital gift is revealed when the recipient creates the correct shape. This personalised unwrapping experience was seen to be appropriate in an intimate relationship when a peer shares common codes that would arise from conversation in the course of dining.

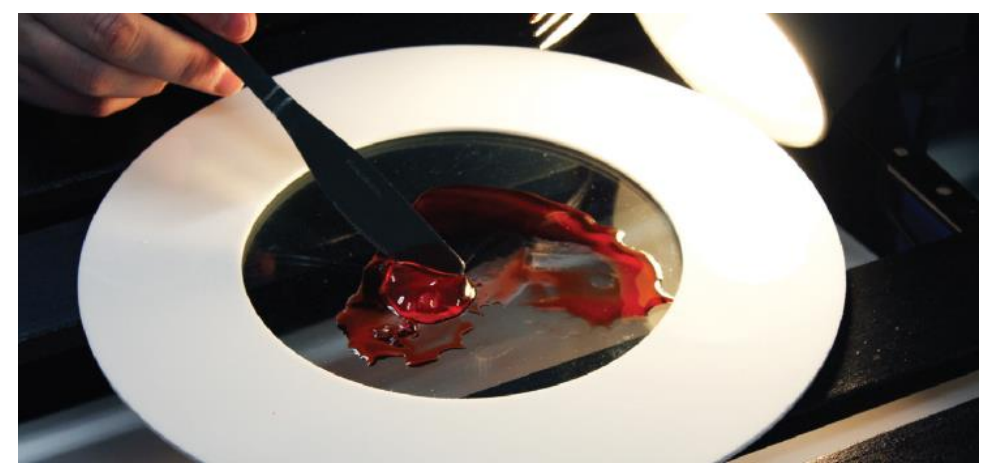

Figure 7. A participant drawing a heart symbol with the dessert, suggesting the symbol as a key to open the gift.

This case study explored how we can design personalised wrapping and unwrapping experiences with a food material. One might personalise artisan food gifts, such as, ice cream and chocolate, by embedding information about the origins, associated stories, personal messages from the giver, and personally crafted musical gifts. Additionally, it is important to design the unwrapping action that would spontaneously arise in the course of dining rather than as an obtrusive step. Moreover, our case study suggests that adding an effortful interface into tangible manipulation would enhance excitement of receiving the digital gift when executed successfully. 


\subsection{The Museum GIFT App - gifting personalised museum tours}

The Museum Gift app, our third case study, allows museum visitors to give and receive personalised minimuseum tours as gift experiences. The app has been designed by the artists Blast Theory as part of the European Horizon 2020-funded GIFT project (https://gifting.digital). Blast Theory based their design on prior research by Lesley Fosh and colleagues into the gifting of personal interpretations of galleries (Fosh et al., 2014), as well as follow-on work directed at gifting in group visits (Fosh, Benford \& Koleva, 2016) which demonstrated how gifting might help address two key challenges faced by museum curators: fostering visitor interpretation and delivering personalised visits. Fosh et al's exploratory study had involved researchers conducting workshops with visitors to guide them through choosing exhibits for significant others and adding personal messages, the results of which were then hand-assembled by the research team to create personalised mini-tours. Blast Theory chose to automate this approach, delivering a scalable app to guide givers through the process of making, giving and experiencing personalised tours.

Figure 8 summarises the concept of the app, the 2018 iteration of which is also explained in the associated video3. In the latest iteration (2019), which more closely aligns with the planned final version of the app, museum visitors are invited by the museum's front-of-house staff and/or an explanatory card to access a webpage. There they find a browser-based app on which they can receive a gift made by the museum curators and create a personalised gift of their own for a friend (a term including family members, colleagues. etc.). The primary interface for the app is audio, accessible with or without headphones. A gift is the giver's photos of up to three objects of their choice, each accompanied by an audio recording of why that object was chosen. The museum's gift is of course not personal in the same way, but is the curator's unique aesthetic and emotional response rather than a traditional delivery of information. The museum gift also sets expectations of what visitors can expect in making a gift.

Visitors who choose to give a gift hear a friendly, slow-paced narration framing the experience in terms of thoughtfulness and care, and are first asked to think of a friend to make a gift for. The chosen receiver becomes the 'filter' through which givers explore the museum and view its collections. The app uses the giver's smartphone's own camera and microphone to allow them to take their own photos (except where not permitted by museum policy) and record their audio explanations. If givers feel uncomfortable speaking in front of the object, they can find a more discreet place (Figure 9). They can re-record as often as they like, and to other visitors they seem to be doing nothing more odd than leaving a voicemail message. They are also asked to type in a clue of how the receiver can find the object. They can repeat this process for a second or third object within one gift. The gift concludes with the giver typing in their name.

Once the gift has been completed, the giver can send the receiver a link to the gift via SMS, email, WhatsApp, or Messenger, services chosen for their one-on-one capabilities, although either party could later share the gift more widely if desired. Receivers can then have the converse experience to givers, also following a voiceover soundtrack that guides them through their experience. They can follow the giver's clue as to where to find each selected exhibit and once found, click to play the audio recorded for them by the giver, repeating this process for any second or third objects that might have made up their gift. They are then asked to record a message to be sent to their gift-giver by way of acknowledgement. They are offered the opportunity to create a gift of their own, although reciprocation is not presented as an integral part of the experience of receiving. In fact, receivers can see and hear the contents of their gifts remotely, although the voiceover encourages an in-situ experience.

3 https://vimeo.com/298647523/8679ad1d99 


\section{Giver}

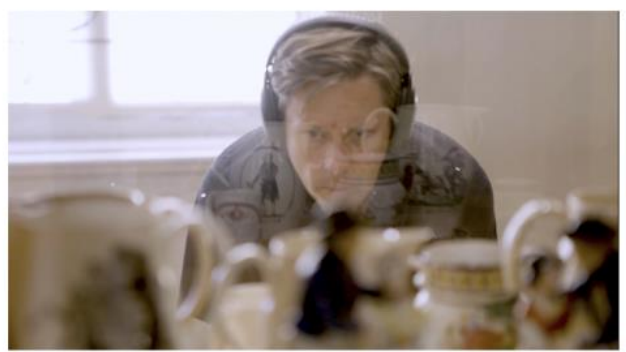

Think of someone and search the museum for items they would like

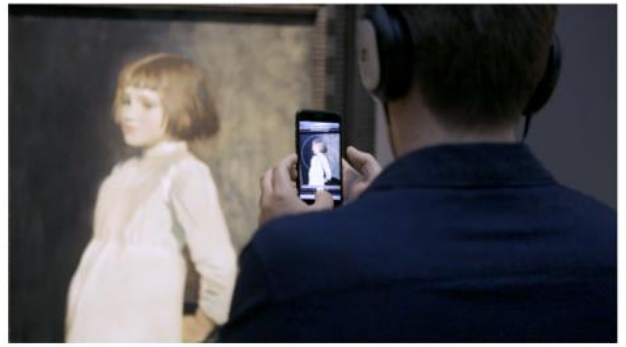

Take photos so they can find them

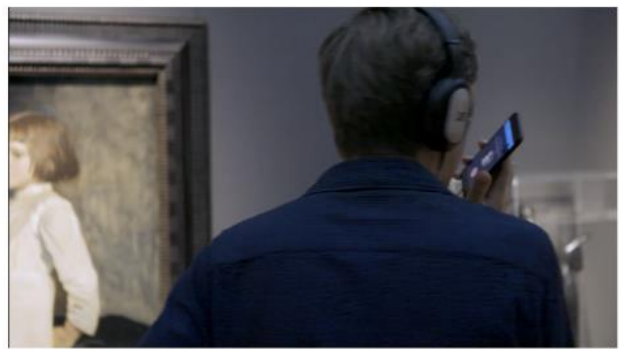

Record personal messages
Receiver

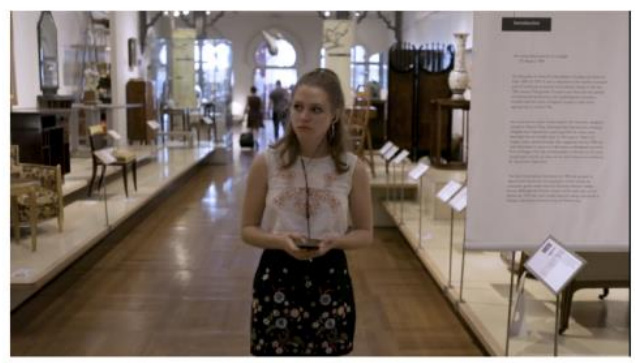

Search out the items you have been given

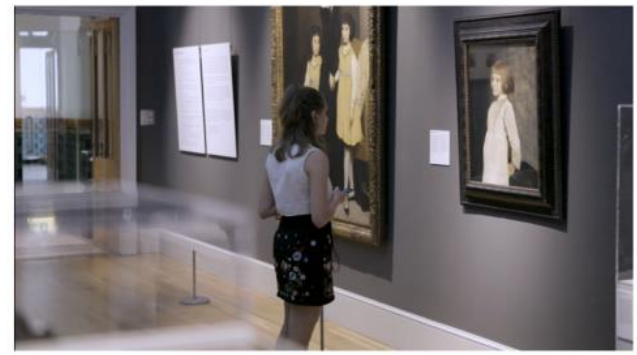

Listen to the messages

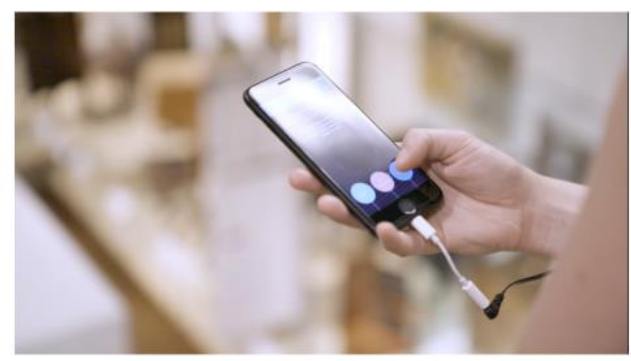

Record your response

Figure 8. The Museum GIFT app concept.

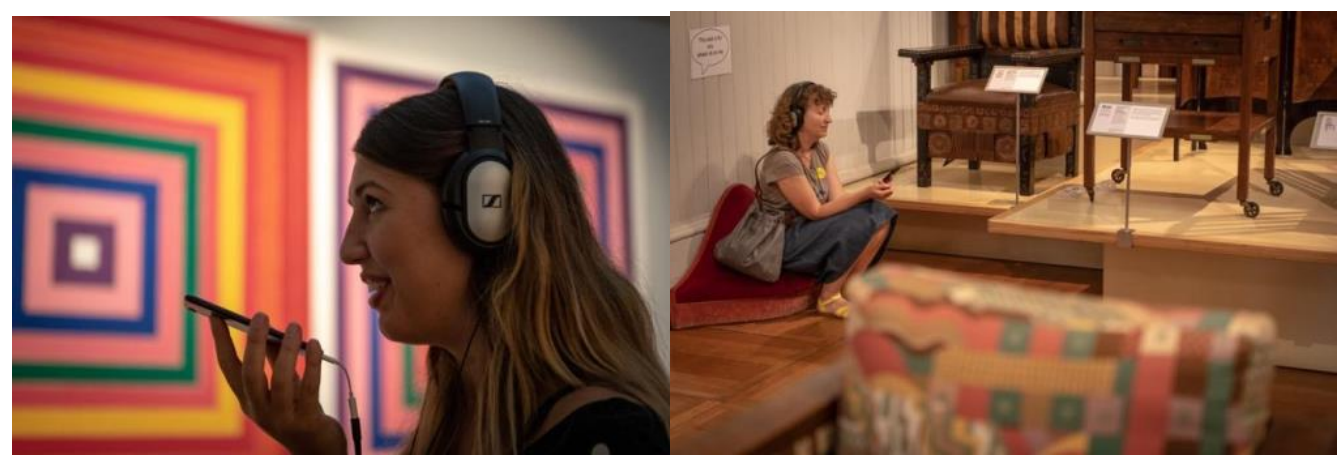

Figure 9. Speaking and listening in the museum space. Photos by Charlie Johnson 


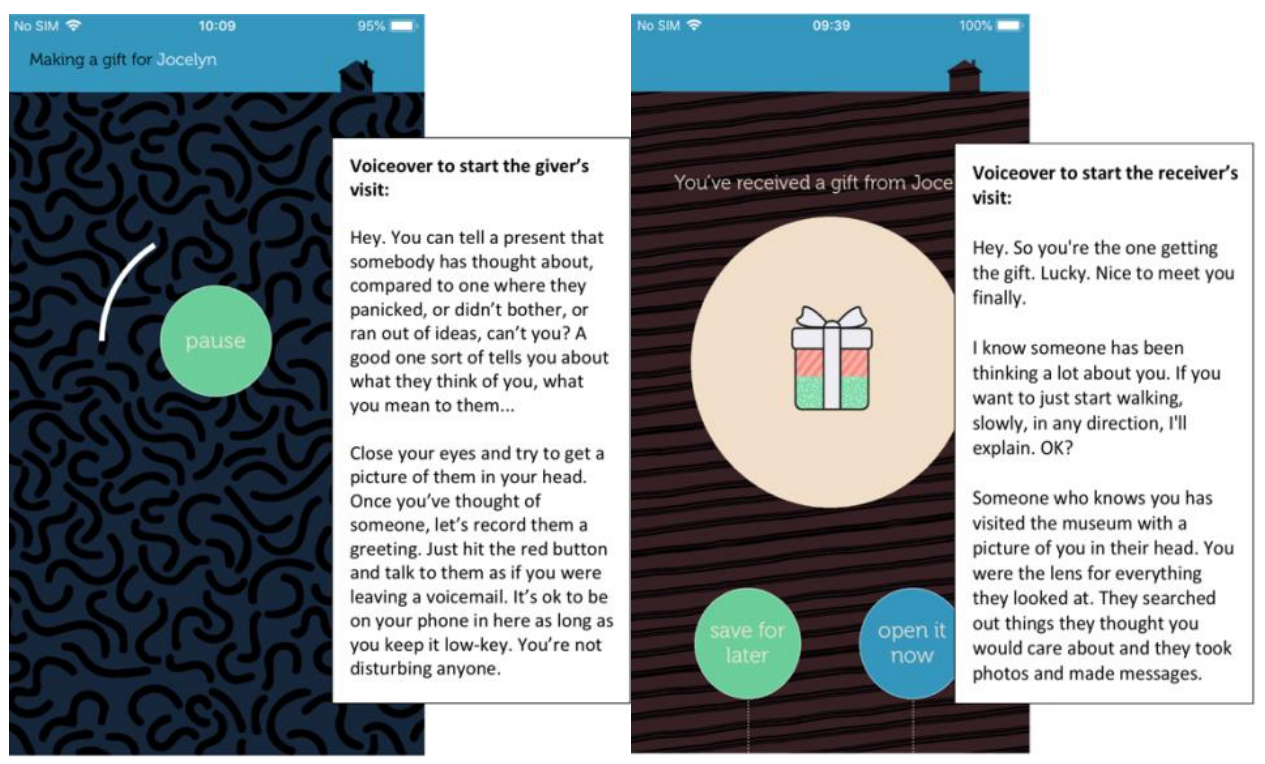

Figure 10. The beginnings of the giver and receiver experiences annotated with examples of voiceover instructions (visual interface from 2018 version)

We highlight two important aspects of Blast Theory's design rationale. First, they considered personalisation and interpretation of the museum visit to hinge on visitor-visitor relationships rather than visitor-exhibit relationships. This meant that they adopted a strategy of 'recipient design' (Fosh et al., 2014, p. 632) in the sense that the selection and interpretation of exhibits was oriented towards a specific recipient rather than towards an official interpretation from the museum or a more general visitor demographic or persona, as is often the case with contemporary museums and cultural heritage institutions (Goulding, 2000). The app was designed to scaffold, not dictate, the giver's interaction with the museum's contents in order to invite an interpersonal interpretation - i.e., what each individual giver idiosyncratically viewed as important for their recipient and why. Blast Theory wanted that interpretation to be more than a simple exchange of information: each interpretation should have emotional, embodied, and experiential characteristics for each individual involved, which would reflect and possibly impact their relationship (see e.g., Richins 1994; Sherry 1983; Camerer 1988; Lawler \& Yoon 1993; Ruth, Otnes \& Brunel 1999).

Second was their distinctive use and treatment of audio, manifest in the voice over (Figure 10), having visitors record audio messages for one another. The scripting and tone of the voiceover was especially important, being somewhat intimate, oddly personal and certainly not seeming like an official guide. Indeed, while the voiceover appeared to be something of an expert in the personal elements gifting, it offered no knowledge of the museum or its contents, coming over as something closer to a personal shopping assistant.

The app was studied during an 'in the wild' deployment at Brighton Museum and Art Gallery over three days in July 2018 where 57 users completed an exit questionnaire and a further 57 undertook a full interview. The findings, fully reported by Spence et al. (2019), revealed how the experience led many visitors to see the museum and its exhibits "through others' eyes", which involved looking at exhibits in new ways by considering the perspective of a chosen gift recipient rather than their own perspective or the official interpretation as given by the museum's curators. Gift givers reported feeling personally connected to artefacts within the museum, though these connections were often conflated with their personal connections to receivers. The experience was often described as being 'emotionally meaningful' and 'intimate'. Participants expressed diverse opinions as to how it related to a more conventional museum visit, with some seeing it as being a 'fresh eyed' tour that gave them the freedom to explore in new ways, while others saw it as more of a distraction from the museum itself. Finally, Blast Theory's distinctive use of voice, both to deliver instructions and often to successfully coaxing participants to record personal messages in the public space of the museum, was viewed as an important element of the experience. 


\subsection{The Rough Mile - a musical city walk to give and receive}

Our fourth and final case study, The Rough Mile, also focuses on the exchange of digital music and the creation of gifts by exploring a physical environment, this time through a physical performative walk through a city that drives both giving and receiving (Figure 11). Our focus was on how to contend with wellestablished norms of digital music sharing, such as posting a link to a song on social media (resulting in no financial outlay and minimal work), or sending a voucher to an online retailer of digital music (resulting in as much financial outlay as desired and minimal work). It would be easy for anyone familiar with contemporary methods of sharing digital music files or playlists over the Internet to select six songs and deliver them to their friend using their own libraries or accounts to prompt their selections and facilitate nearly effortless sharing. However, Leong and Wright (2013) have documented how the effortless sharing of digital music can be perceived as insufficient substitute for personally meaningful gift-giving, a finding in line with Brown and Sellen's (2006) early observation that the automation of the act of choosing music files to be shared minimises 'the social importance and meaning of music', such that the focus of design should be 'technologies which seek to mediate the choice rather than simply automate it' (p. 90). We therefore sought to carefully mediate the process of choosing songs, thereby aiming to achieve or at least approach a personally meaningful gifting experience.

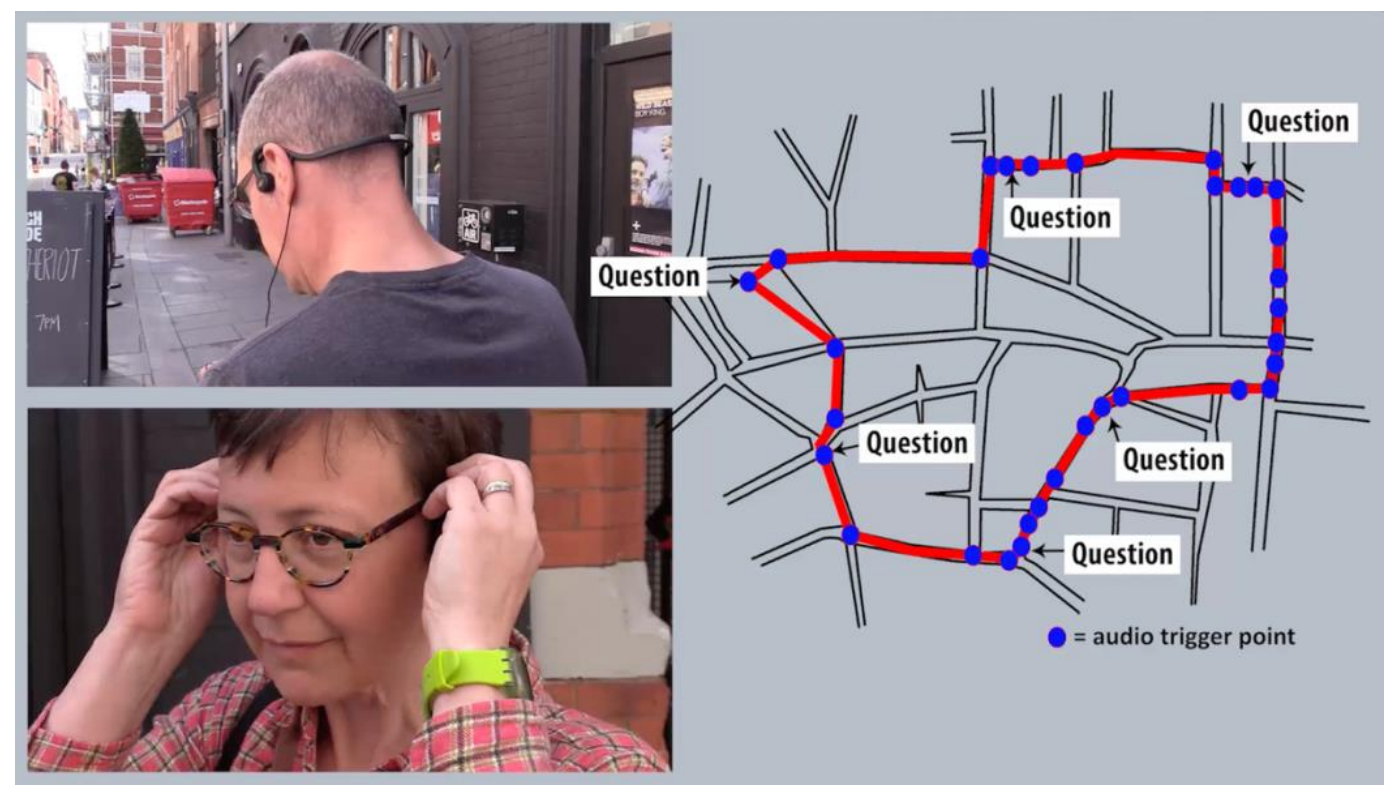

Figure 11. Giving and receiving locative music playlists in The Rough Mile

The Rough Mile was a two-part experience designed for pairs of friends to create a gift for each other and, in the second part, to experience the gifts they had created for each other. Part 1 - gift creation - took the form of a locative audio walk, a physical walk through a city that employed locative media technologies and theatrical performative strategies to engage givers in the task in composing a personalised music playlist for their chosen partner. This comprised five layers of audio - a narrative story, questions, music tracks chosen by us, some pre-recorded ambient sound, and also the natural ambient sound of the city (accessible through the use of bone-conductive headphones that do not block the ears). These were combined with visual and other physical sensations of navigating the route. Each participant walked the route alone, listening to the audio, which at key moments, asked them six questions to which they responded with the title and artist of the song they would want to give their friend in that situation. Twice along the route, participants were interrupted by actors playing characters in the narrative, who captured the details of the songs they had chosen so far, along with their reasons for choosing them, as audio recordings. Part 1 therefore captured a playlist of songs along with recorded reasons for giving these that were associated with key locations in the city. 
In Part 2, the pairs of participants returned to walk the same route, but this time 'receiving' (listening to) the gifts that had been chosen for them by their friend. The resulting audio gift (that the research team had carefully assembled in the intervening time) consisted of the six songs for the friend to hear, each one introduced by the question posed in Part 1 and recorded snippets of the rationale behind each choice as recorded during Part 1. At the end of Part 2, the pair met up in a café to discuss their gifts which each other (which also provided data for a study of the experience). We draw attention to three features of this unusual design.

First, we deliberately created a multisensory and theatrical experience so as to emotionally engage givers and receivers. A detailed breakdown of how immersive theatre practices informed the design of The Rough Mile can be found in Spence et al (2017). In brief, Part 1 immersed our participants in a multisensory experience that would direct their attention towards gifting on multiple levels. First, the project required participants to arrive in pairs that would exchange gifts, establishing a gift-giving context that permeated the locative audio walk (Part 1). The audio content of Part 1 included an overarching linear story in which the narrator described the difficult situation her friend found himself in and her desire to overcome a rift in their relationship by giving him a meaningful gift. The questions prompting participants to think of music tracks were phrased very specifically to reflect the narrative at that point in the process. The situations underpinning each question appealed to the participants' embodied sensations of occupying an evocative public place while also being reflected in our choice of background music. For example, at one point, participants walked uphill along a shadowy back alley, listening to the narrator describe a difficult point in her friend's life. The back alley opened up into an open, populated (and sometimes sunny) road with a tram stop. The question asked participants to choose a place they wished the tram could take them and their friend to, and then to come up with a great song for them to listen to there.

Second, we designed a reciprocal structure that participants did as pairs, but that carefully balanced when they were together and then they were isolated. Pairs of participants arrived together and were interviewed afterwards at the same time, such that they left together as well. However, participants were sent out individually, several minutes apart, so that each participant could devote time and energy to thinking of the other while also maintaining an element of surprise. This combination of the private and the shared gave participants the opportunity to enjoy both parts of the walk for their own sake while anticipating how their friend would respond, wondering what songs their friend would choose, and hoping their friend would enjoy the selections being gifted to them.

Third, as a technical note, we employed an 'adaptive audio' player as reported in (Hazzard et al 2016) to synchronise the music tracks to key segments of the walk. This remixes and edits music tracks on the fly, shortening or extending each one (e.g., chopping our sections or looping others) as required so as to fit the pace of the walker and deliver an (ideally) seamless transition between pairs of tracks at a key waypoints (for example on turning a corner or entering a square or courtyard).

Spence at al (2017) describes a study of The Rough Mile in which 26 participants (13 pairs of friends and romantic couples) were interviewed after each part of the experience (giving and receiving). Participants commented positively on the bodily experience of the city walk as a way of framing the gifting experience rather than, say, gifting via an online service. Again, sound proved to be an important and 'sensual' element of the experience, and the use of the bone conducting headphones to mix narration and designed sounds with the natural background soundscape of the city was especially appreciated. Participants draw on both the narrative but also the features of the landscape to inspire their choices of songs as gifts. However, the use of live performers was largely seen as a negative aspect of the experience, with 14 participants reporting that it ruptured their engagement.

22 of the 26 participants reported that they had come up with satisfactory gifts for their partners. However, there was clearly a degree of anxiety involved in making the right choice and in subsequently sitting down to discuss the gifts together afterwards. One participant in particular was 'a bit insulted' when called 'materialistic' by his girlfriend and another felt his girlfriend had put so little personal effort into her gift to him that he went away, reflected on their relationship in light of this insight, and subsequently broke up with her. He assured us that the experience neither caused nor contributed to their breakup, but it certainly did 
provide the opportunity for him to contrast his commitment to the 'contract for participation' with his girlfriend's, and find hers wanting.

\section{DISCUSSION - CONCEPTS FOR HYBRID GIFT EXPERIENCES}

We now reflect on our design portfolio to draw out wider principles for the design of gifting experiences. The following discussion explores this idea from three perspectives. First, we introduce the idea of hybrid wrapping in which physical gift items are first wrapped in digital media (or vice versa) by a giver, before subsequently being unwrapped by a receiver as part of a personalised gift experience. Next, we consider how gifting experiences can encourage the expenditure of effort by both givers and receivers in a way that is both visible and pleasurable. Finally, we consider the consequences of this for obligation, discussing the design tensions of acknowledgement versus reciprocation; awkwardness; and gifting versus sharing. By way of an orientation to our reflections, Figure 12 presents an overall summary of our annotated design portfolio, associating each of our four designs with the key themes that emerged from our reflections as we now consider in greater detail.

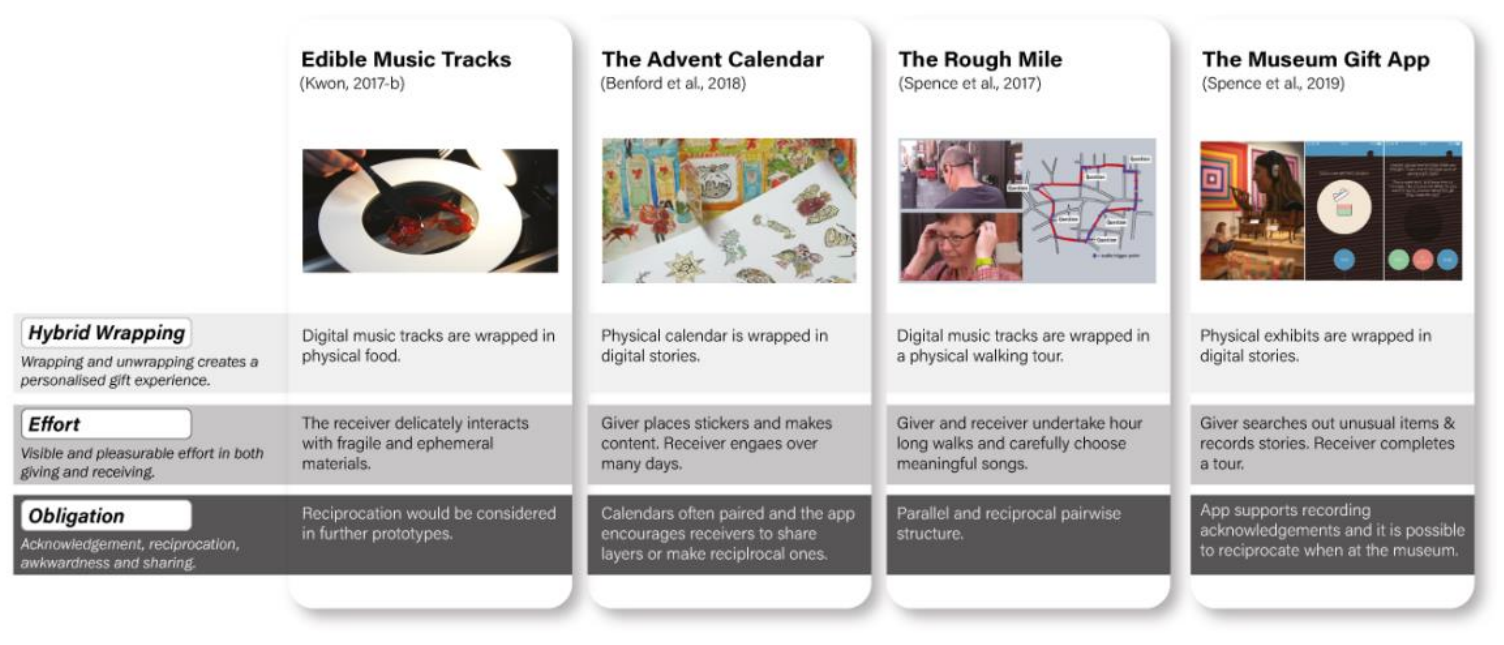

Figure 12. Our annotated design portfolio

\subsection{Hybrid Wrapping}

A key contribution of our paper is to propose the idea of hybrid wrapping in which - analogously to the way in which traditional gifts are often wrapped in paper and other materials - digital technologies become involved in the wrapping of gift items to create gift experiences. As discussed in the literature review, wrapping is an important aspect of gifting, being practiced in many cultures and serving to personalise gifts, convey the effort involved, and generate suspense and surprise for the receiver. We adopt the term hybrid wrapping to capture the idea that gift items and/or the wrappings may potentially be both physical and digital. Our portfolio shows how physical gift items may be digitally wrapped with personal stories, music and other media, while a digital gift item may be wrapped in physical materials such as food that reveal the gift as they are consumed.

\subsubsection{Wrapping as an example of hybrid layering}

As discussed in the literature review, the concept of hybridity and especially of physical-digital layering is already familiar to HCI. All of the examples in our portfolio involve layering of one form or another, connecting physical and digital media materials and/or artefacts to create new experiences.

Each of our prototypes illustrates a different approach to employing layering to deliver hybrid wrapping in terms of what is wrapped and what it is wrapped in. In terms of the kind of gift that is wrapped, both the Edible Digital Gifts and The Rough Mile begin with the selection of digital gifts, specifically one or more 
music tracks. We conceptualize these digital gifts as then being wrapped in physical artefacts (food) and physical walking experiences respectively. Through receivers interacting with the physical wrapping (consuming food and walking) the digital gifts are revealed and remain in the user's collections. Conversely, the Advent Calendar and Gift museum app begin with physical gifts, a traditional paper artefact in the former case and an embodied museum visiting experience of choosing physical objects in the latter. These are then wrapped by the givers in layers of personalised digital content. At the end of the gifting experiences the original gift items (the advent calendar and the museum artefacts) are left unchanged and ready to be reused (by being wrapped in new content). Thus, as Table 1 shows, a hybrid wrapping can involve wrapping a physical gift item in digital wrappings or vice versa, while the gift items or wrappings may be both artefacts of experiences. We acknowledge, however, that this is a simple classification and the receivers' perception of the gift and wrapping may be fluid and contextual, seeing what we classify as wrapping as a key component of the gift. While this is more likely to be a feature of hybrid gifts, there are also examples of more complex relationships between traditional (purely physical) wrapping and gifts (e.g. in Furoshiki, the Japanese art of fabric wrapping, or children preferring to play with the packaging rather than the enclosed toy).

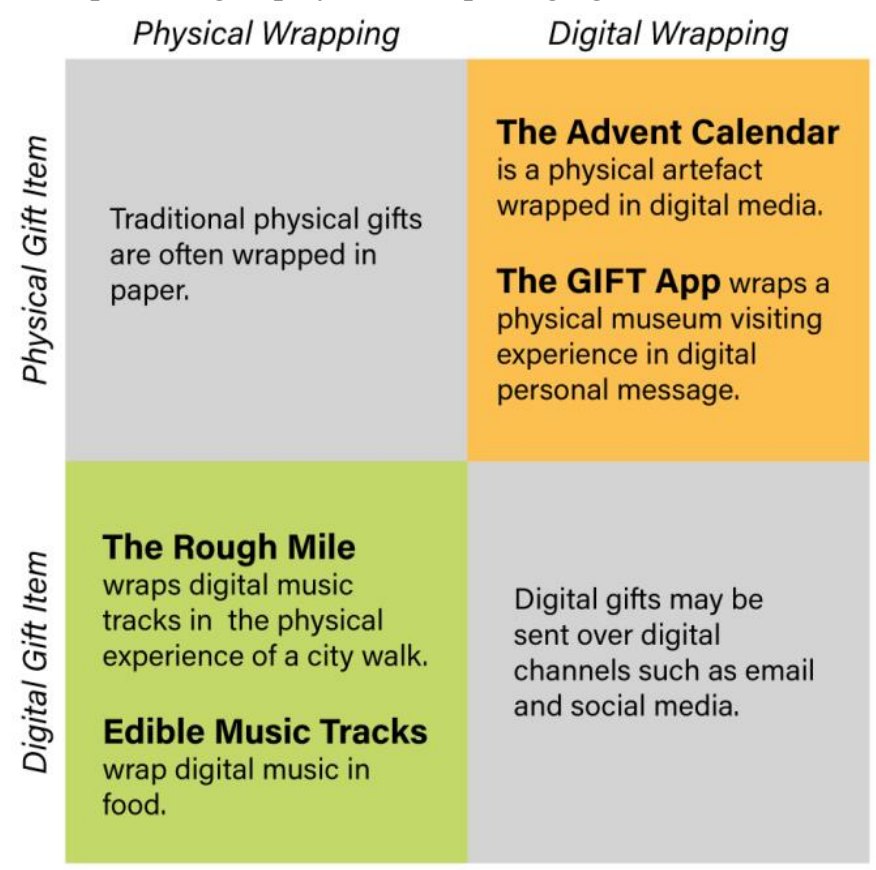

Table 1. Hybrid wrapping of physical and digital and vice versa

Kwon's previous study discussed earlier (Kwon et al., 2017-a) revealed the overall experience of current digital-only gifting (bottom-right quadrant) to be generally weaker in terms of the engagement of both givers and receiver throughout the experience when compared to traditional physical gifting (top-right quadrant). We propose that the hybrid gifting strategies (top right and bottom-left quadrants) offer an interesting route to bridging this gap by bringing important physical sensory qualities such as touch, movement, and taste into digital gifting experiences, reflecting wider arguments in $\mathrm{HCI}$ about the importance of physically embodied sensory experience.

\subsubsection{The trajectory of wrapping}

Kwon's study (2017-a) also considers gifting as a process that unfolds over time, passing through the different stages of preparation, exchange, reveal, use and reflection. This leads us to consider the dynamic nature of wrapping in which gifts are wrapped in order to subsequently be unwrapped as part of an overall gifting experience. A distinctive feature of hybrid wrapping, as a form of physical-digital layering, is therefore its temporary nature. Rather than striving for a permanent or deep connection of the physical and digital into a new 'thing', our examples all involve making short-term and superficial connections between a thing and its 
wrapping. As with traditional paper wrapping, the wrapped item emerges intact at the end of the experience and is known to exist inside the gift (even if it is temporarily hidden or disguised). Furthermore, depending on how it is treated, the wrapping may also survive the experience.

Previous research has argued for approaching the design of hybrid user experiences in terms of trajectories that interleave physical and digital layers over time (Benford and Giannachi, 2011). We draw on this approach to propose the general trajectory for hybrid wrapping (and unwrapping) shown in Figure 13, overlaying this on Kwon's proposed five stages of the gifting process.

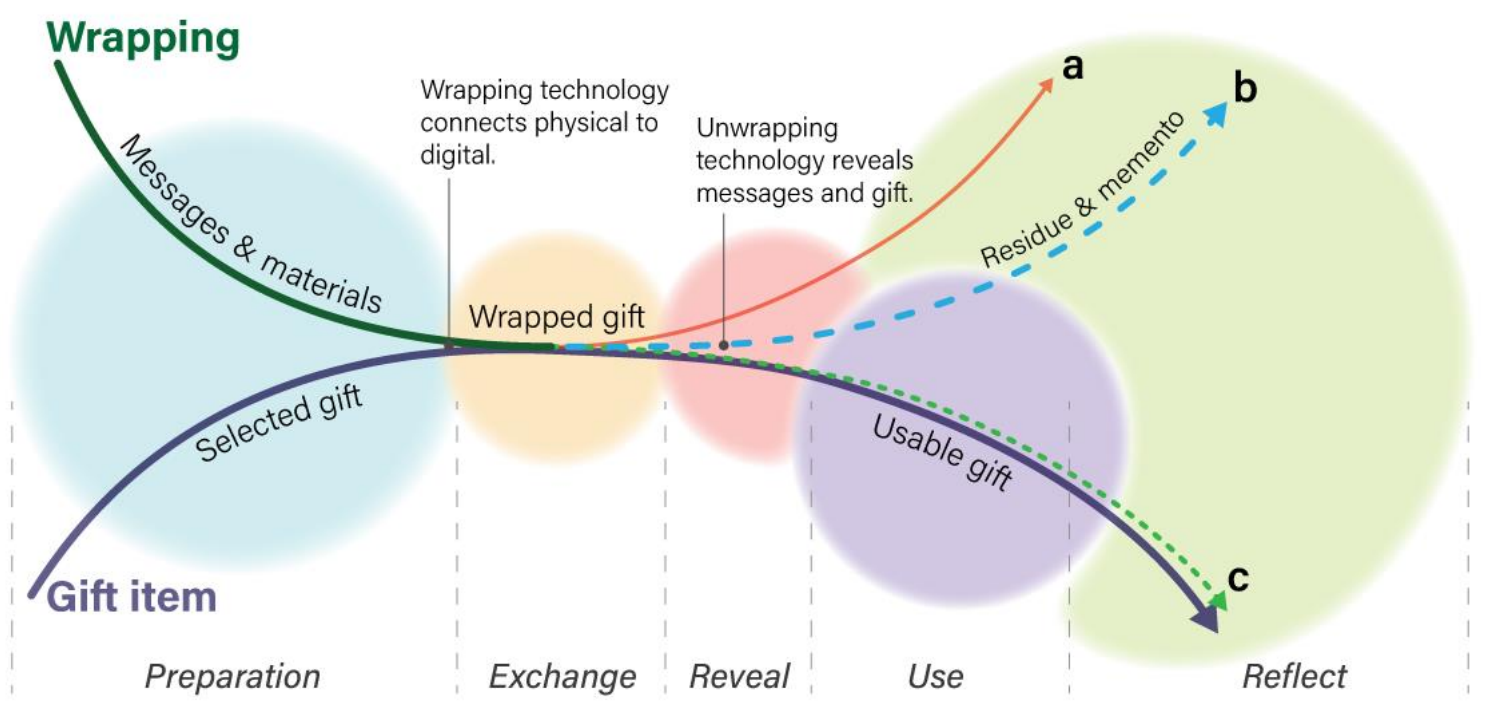

Figure 13. The trajectory of hybrid gifts. Hybrid gifts are comprised of Gift item and Wrapping. Both gift item and the wrapping get selected and personalised during the Preparation phase and connected to each other through the wrapping technology. After the gift has been exchanged, the wrapping takes different routes depending on how they form the hybridity of the gift. (a) Some wrappings enter Reflection phase directly after being Revealed, (b) some others are being used while detached from the gift item and become a memento, (c) wrappings that are ultimately blended with the gift items follow the same trajectory of the gift item.

While we adopt Kwon's five-stage gift exchange model, the trajectory of the hybrid gift accommodates fuzzier boundaries between the stages, especially, in Reveal, Use, and Reflect. We suggest that hybrid wrapping can take different routes depending on how it is associated with the gift item and especially what happens to it following unwrapping. (a) Some wrappings will remain as a memento right after being unwrapped without being practically used. This can be seen from the typical gifts wrapped in conventional wrapping paper or gift bags. The hybrid gifts introduced in this paper took either (b) or (c) routes. Wrapping was either (b) partially incorporated in the use stage, or (c) fully blended with the gift item. At the end of the experience the original gift item is left unchanged and ready to be reused or reflected on. The wrapping might also leave a residue that can be kept as a souvenir of the gift experience. For example, personal messages might (ideally) remain accessible in some way to be replayed, reflected on and shown to others, while some part of a physical wrapping may remain behind as an anchor for accessing these in the future. This residue could be an important enabler of the so-called historic trajectory, that is the recounting of an experience to others after it has happened (Benford and Giannachi, 2011).

Two key 'transitions' (a key concept of trajectories) along this journey are the moments of wrapping, in which the giver employs an interactive technology to associate the gift item with surrounding materials, and unwrapping, in which the receiver uses a corresponding technology to unwrap and reveal the gift item while also experiencing the surrounding materials, for example, playing personal messages while eating food. Three of our prototypes use (different) apps to achieve these transitions of wrapping and unwrapping. The Advent Calendar uses the Artcodes app to both wrap and unwrap the gift; The Rough Mile uses a GPS-driven 
locative audio app, the Gift museum app allows visitors to manually choose when to reveal messages. The Edible Digital Gifts, on the other hand, uses sensors embedded into tableware to support the moment of unwrapping.

The temporal aspects of hybrid wrapping may enable suspense and surprise in which the wrapping obscures the gift item to some degree after it has been exchanged but before it is revealed. It is easy to see how this can be achieved when digital gifts are physically wrapped as interacting with the wrapping may conjure up the digital media for the first time (leaving it as being generally accessible thereafter, e.g. adding a new song to the receiver's music collection). It is more challenging to imagine how digital media can obscure physical objects. Perhaps the surprise may lie in revealing personal messages associated with the gift rather than the nature of the gift itself, i.e., the receiver may know what they have been given but not by whom or why until the gift is unwrapped?

It is notable that trajectories were first introduced as a way of describing 'mixed reality performances', experiences that not only combine the physical and digital but that typically also involve the use of theatrical and performative tactics to deliver a compelling user experience. Our case studies also employ these kinds of tactics. The Rough Mile in particular, involves a framing narrative, the use of live performers on the streets and other theatrical tactics (Spence et al., 2017) with the view of placing both giver and receiver in an unusual emotional state in which they can reflect on a gift created for or by another. The Gift museum app employs a similar approach (if more subtly) in the design of its narrative, drawing on Blast Theories heritage in designing many of the experiences that inspired the trajectories conceptual framework (Benford and Gianacchi, 2011). Thus, the designers of trajectories of wrapping and unwrapping may wish to consider how to make these performative experiences in order to heighten the emotional impact of the gift. In turn, some of the examples in this paper point towards the translation of ideas from HCI's engagement with the performing arts into more mainstream applications - in this case the design of gifting services.

Broadening our perspective beyond HCI for a moment, we can relate this discussion of hybrid wrapping to the concept of product-service systems from the disciplines business and marketing. The strategy of enhancing the attractiveness of a product through additional service offerings is referred to as servitization (Vandermerve and Rada, 1988) and has led to the emergence of the concept of the Product-Service System (PSS) in which conventional tangible goods are extended through the provision of an additional service. According to Smith et al. (2014) there are various definitions of a PSS: as a value proposition (Tukker and Tischner, 2006), a competitiveness-preserving innovation approach (Manzini and Vezzoli, 2003) or as a conceptual vehicle to develop new ways to serve customers (Bullinger et al., 2003; Mont, 2001). The rationale underlying these ideas is that customer value is determined through the benefits derived from using the product rather than owning it, a notion that underpins the economic theory of durable goods (Waldman, 2003). We suggest that hybridity as discussed in this paper may have a role to play in the delivery of PSS as the services that are bundled with a good (physical or digital) may increasingly be delivered online through digital means. Indeed, the notion of layering services on goods underlies much contemporary thinking about PSS, which sees digital or other services as being hierarchically layered onto a base product (Kotler, 1967; Levitt, 1980). More generally, Arthur (2009) discusses how technologies may emerge as the result of a recombination of other technologies, proposing that technological development forms a process of "concatenation of principles - conceptual ideas - architected together" (p. 129). This may result in stratified product configurations in which one technological stratum can be said to be more basic than another, thereby mapping out relations of emergence (Simon, 1969). Another established avenue of research in the field of marketing concerns the importance of 'experiences' as part of the experience economy. Experiences are products that are designed to be memorable (Pine and Gilmore, 1998), engaging consumers senses and emotions, an idea reflected in HCI's discussions of interactive 'user experience' design (McCarthy and Wright, 2007). Following these lines of thought, the idea of digital wrapping as proposed in this paper provides a technical means for realising new kinds of stratified gifting products, especially ones that transform combinations of physical and digital goods and services into memorable user experiences. 


\subsection{Effort}

So far, we have focused on hybrid gifts as products - that is on the things that are given and received and consequently wrapped and unwrapped in hybrid wrappings. Another important perspective on gifting highlighted in the literature is as a social process - a transaction between giver and receiver. How might a consideration of the social aspects of gifting further inform our thinking about hybrid gifting experiences? We begin by considering the importance of effort.

\subsubsection{Expending effort in both giving and receiving}

Our various prototypes encourage givers to expend effort at several points during the gifting trajectory. First, there is effort involved in selecting or assembling the gift, for example by undertaking a city walk in The Rough Mile in order to choose music tracks, or by exploring a museum to select the artefacts to appear in a personalised tour. Our prototypes encourage the giver to then expend effort to prepare and wrap their gift, for example capturing photos and configuring the physical aspects of the Advent Calendar, or recording personal voice messages in the Gift museum app. Receivers may also be required to expend similar effort to unwrap the gift, for example undertaking same city walk in order to listen to music tracks in The Rough Mile or (ideally) exploring the museum to find the objects that have been chosen for them.

Seen from an HCI point of view, our designs are examples of 'effortful' interfaces that deliberately require users to expend effort to use them rather than making interactions as 'easy', 'efficient' and hence effort-free as possible. Our portfolio therefore illustrates a further use for effortful interfaces as previously discussed in $\mathrm{HCI}$ (see literature review) in which expending effort increases the social value of an interaction, in our case by adding value to a gift. Our prototypes demonstrate how hybrid wrapping can elicit the giver's effort and skills (e.g. in the preparation of digital media), as is often the case in physical gift wrapping. It should therefore not be (or appear to be) trivial or instantaneous to apply (e.g., through a single 'click') but should instead involve an element of creativity, for example selecting, applying and 'mashing up' digital media such as personal photo collage or integrating VR/AR video contents that enhance the 'use' experience of the gift item. Of course, while increased personal effort invested in making the gift should be encouraged, the effort in using the designed service in order to make this investment should not also increase. As Blast Theory saw in the difference between the 2018 and 2019 versions of their Gift museum app, reductions in the effort to access or use the app itself lowered barriers to uptake and increased overall satisfaction.

\subsubsection{Making effort visible}

Not only must appropriate effort be expended, but it must also be rendered visible to the other party. For example, the giver's rationale for selecting gift items needs to be captured ("I chose this because I was thinking of you") as should their skill in hybrid wrapping (composing or selecting digital media). Food appears to be one kind of gift item that is 'ripe' with the potential for displaying effort and also for digital intervention, as shown by our Edible Music Tracks case study. Home-made or personalised artisan foods are routinely exchanged as gifts on special occasions and food offers many creative elements, such as type, size, shape, colour, and flavours, that allow a giver to expend and show effort, while following a recipe to prepare and present food mirrors the effort put into the preparation of a gift.

Receivers' meaningful reflections on their experience of the gift also need to be made visible. As a result, the designers of gifting services may consider making them not only efficient and convenient with respect to giving and receiving, but also to steadily inspire people to build long-term engagements with the gifts throughout all five stages of gifting. For example, one might create a notification system in a music player that reminds the receiver of the occasion that the music track was given and offer a chance to feedback or reciprocate.

\subsubsection{Making effort pleasurable}

Expending this effort should be pleasurable in and of itself. The acts of selecting and wrapping, for example, need to be made enjoyable experiences in their own right rather than difficult chores. We suggest that people gladly expend extra (or even excess) effort on things that are fulfilling and meaningful to them, for example taking the trouble of hand-making a card partly to personalise the gift, partly to demonstrate the amount of effort that has been put in, and partly for personal satisfaction in having expended effort in an act of love or 
generosity towards the recipient. Thus, effortful interactions need to reward both parties in a social transaction such as gifting.

The Rough Mile in particular provides a case study of how designers might approach the challenge of designing visible and pleasurable effortful interactions for gifting. The primary rationale underlying the prototype was to increase the effort involved in creating a gift of digital music. For this we turned to techniques employed to engage audiences in immersive theatre, in which 'the physical insertion and direct participation of the audience member in the work must be a vital component and is a defining feature of this particular strand of visceral practice' (Machon, 2013, p. 57, emphasis in the original). In particular, participation in immersive theatre goes beyond the simple following of instructions: the participation must be constitutive of the work (Alston, 2016) so that, without it, the designed experience would not exist as a coherent whole. Participants in The Rough Mile had to make a physical effort to move through the space in such a way that the audio would be triggered, and for the audio and location to reflect and amplify each other. More importantly, though, they had to invest mental and emotional effort in coming up with song selections and rationales that formed the gift. The participants in our study agreed that this considerable expenditure of effort was worthwhile; every single one felt that a purely online version with no physical element and every opportunity to facilitate easy song selection would be pointless. Effort in terms of making things difficult for no reason would still seem to deter interaction, while effort in terms of soliciting creative participation seems to invite enjoyment, investment, and the potential for personally meaningful gifting experiences.

More generally, we suggest that it is this effort involved in both the giving and receiving of goods that adds value both to the social transaction that is the gift, but also to the objects that are gifted. As Graeber (2001, p. 45) observes: 'Commodities have to be produced (and yes, they also have to be moved around, exchanged, consumed, etc.), social relations have to be created and maintained; all of this requires an investment of human time and energy, intelligence, concern. If one sees value as a matter of the relative distribution of that, then one has a common denominator. One invests one's energies in those things one considers most important, or most meaningful." This builds on Annette Weiner's (1992) argument that the value of objects of "transcendent value" would simply be an effect of all the efforts people have made to maintain, protect, and preserve them. Even if, from the point of view of the actors, the sequence seems as if it's precisely the other way around.

\subsection{Obligation}

While effortful interaction would appear to be a potentially powerful concept to employ in the design of future gifting experiences, it comes with a cost. One consequence of expending effort in gifting is social obligation, in which the other party feels obliged to respond to that effort in an appropriate way, specifically though a combination of acknowledging the gift; expending effort in receiving and using the gift; and perhaps even reciprocating with a gift of their own. Gift exchange is strongly tied to creation and maintenance of relationships, of which fulfilling social obligations is an important part. Moreover, with obligation comes the risk of social awkwardness and embarrassment, requiring designers to support receivers in meeting their obligations and/or otherwise mitigating the attendant risks. We now consider three design tensions that impinge on this.

\subsubsection{Acknowledgement versus reciprocation}

A baseline level of obligation lies in acknowledging a gift, at least to the level of recognizing and initially responding in an appropriate way. Opportunities for receivers to generate acknowledgements might potentially arise at multiple stages of the gifting trajectory: they might acknowledge receipt of the gift, the quality of its wrapping, express anticipation of opening it, share the delightful surprise of unwrapping the gift, comment on its subsequent use, or even reflect on it long afterwards. Digital services might provide multiple opportunities for capturing and sharing such acknowledgements throughout gift exchange, thereby enhancing engagement with digital gifting.

Beyond acknowledgement may lie an obligation to respond with a further gift in return. Of course, gifting does not always lead to reciprocation and even when it does occur, may also involve the giving of a different kind of gift. This said, our prototypes do suggest opportunities for hybrid gifts to support reciprocal 
exchanges around common gift items. The Rough Mile directly experimented with a reciprocal structure in which couples acted in parallel as both givers and receivers of mutual gifts grounded in a common experience of a city walk. The Advent Calendar encouraged its owners to make and exchange different digital layers between sets of physical calendars, which became connected as a result. The Gift museum app encourages the receiver to visit the museum to use their gift, at which point they are encouraged to create a reciprocal interpretation for the giver. In each of these cases, the receiver is in a sense giving back the gift - the physical calendar or a museum tour for example - but is customizing it (e.g., choosing different exhibits in the same museum) and also rewrapping it with new personal content.

A further possibility to support reciprocation lies in the wrappings rather than directly in the gift items. Givers and receivers might reuse the residue from previous wrappings to create new wrappings, which might convey digital memories of the previous history of gift exchanges. For example, we envisage reusable hybrid gift tags that carry memories of previous gifts and so provide a shared record of a series of reciprocal exchanges. These might be especially suited to repeated gift rituals such as birthdays and religious or social festivals where a common group of people regularly exchanges gifts. They might even encourage sustainability by rewarding the reuse of physical labels, gift bags and so forth.

\subsubsection{Awkwardness, embarrassment and discomfort}

Opportunities for acknowledgement naturally arise, and perhaps become ever more obligatory, in the course of co-present gift exchange in which both parties can directly sense and respond to the obligation. This suggests the possibility of extending hybrid gift experiences to trigger live connections to remote participants at key moments in the trajectory, for example at the moment of unwrapping. However, we note that this is a 'high stakes' gambit that may potentially backfire if a gift or response is misjudged in some way. In her initial work on designing museum gift experiences for couples, Fosh et al (2014) encouraged giver and receiver to be co-present throughout the experience. She reported how, in one notable case, this led to considerable awkwardness between a romantic couple where the receiver was evidently not appreciative of the gift, which in turn caused embarrassment for the giver, with little opportunity for saving face due to them being copresent throughout the entire time. Our own study of The Rough Mile reported a similar case of social awkwardness when a couple was interviewed about a gift together, even though it had been experienced by the receiver in isolation, and the giver felt their receiver had not invested an appropriate or commensurate level of effort. The designers of hybrid gifting services who wish to enhance co-presence through digital means therefore need to carefully consider how to accommodate potential moments of social discomfort, providing opportunities for gathering thoughts or ways of saving face. Alternatively, Benford et al (2012) have previously argued that a degree of discomfort may be a positive design strategy for promoting social bonding, which suggests an alternative strategy of raising the stakes around co-present gift exchange in some circumstances, though being careful to also provide opportunities for cathartic release and resolution of any discomfort that remains towards the end of the experience.

\subsubsection{Gifting versus sharing}

The gifting literature discusses how gift giving may be part of a wider social occasion, for example festivals and family gatherings, in which gifts are exchanged in the presence of others. Co-presence therefore may extend to other parties beyond the immediate giver and receiver who may witness the gift exchange and are involved in acknowledgement and potentially also in any consequent embarrassment. Hybrid gifting services might also connect these spectators (as Reeves et al. (2005) would describe them) through real-time communications or comments and messages on social media.

However, enhanced dialogue through social networks or shared acknowledgement around gifts should not be confused with shared ownership of them. Digital gifting through email, messaging and other general channels, where the giver is able to keep the original, may engender more of a sense of 'sharing' and potentially devalue the gift because it is not truly given away. Golsteijn et al. (2012) and Kwon et al. (2017a) argued that the shared ownership of some digital gifts (e.g., photos and music files that can be copied before given) seemed to prevent digital gifts from gaining significance in social gifting. Gifting services that transfer not only the digital materials but also ownership may foster a strong sense of a gift. Designers may wish to consider the strategies employed by ephemeral messaging apps (e.g. Snapchat), but in a reversed 
way. For example, when a giver sends a digital gift via an app, once the receiver accepts the gift, it gets removed from the giver's device. In this way, givers might more thoughtfully select and send the digital materials, and the system would convince receivers that the passed digital artefact is a gift that has no other copies remaining in the sender's outbox.

We speculate that there may be an important role for the residue left from the wrapping here which may more easily act as a sharable resource than the gift itself. Thus, designers might consider designing hybrid wrappings that deliberately leave behind digital and physical residues from a gift exchange that can readily be shared without devaluing the gift item itself.

\section{CONCLUSION}

We have created and reflected on a portfolio of gifting experiences as part of a Research Through Design approach. Between them, our four examples illustrate the idea of hybrid gifting, drawing on both the strengths of physical experience and digital technologies to create new gifting experiences. In particular, we have introduced the idea of digital wrapping as a way of temporarily associating physical and digital layers so that one appears to be wrapped in the other. Sometimes a physical gift item is digitally wrapped, but sometimes it is the other way around. We have then explored various design issues for such hybrid gifts including designing trajectories through a gifting process, supporting visibly and pleasurable effortful interactions throughout, and managing the opportunities and tensions arising from social obligation. We end by considering the implications of our work for both practitioners - those who wish to deliver new gifting experiences - and academic researcher - both within HCI and beyond.

Beginning with practitioners, we distil our findings into the following key considerations - by which we mean issues and approaches to consider rather than concrete guidelines - for the application of interactive technologies to future gifting experiences.

1. Combine physical and digital gift items and wrapping materials to create hybrid gift experiences that are both experiential and memorable and that can be delivered face to face but potentially also via online services.

2. Consider gifting experiences to be trajectories that pass through the five stages of preparation, exchange, reveal, use and reflection and then design these trajectories to make temporary associations between gift items and their wrappings, paying particular attention to the two key moments of wrapping and unwrapping.

3. Consider how the wrappings may leave a residue and how this may provide opportunities to support reflection and acknowledgement, or might be reused in future gift exchanges.

4. Enable people to visibly expend effort in both the giving and receiving of gifts and strive to ensure that this is pleasurable, including in the giving of hybrid gifts.

5. Consider the possibilities of reciprocal gifting structures, but also recognize that reciprocation is not the same as acknowledgement and that not all gifts need be reciprocated with the same kind of gift, or indeed at all.

6. Consider how to enhance co-presence when givers and receivers are remote from each other, but also anticipate and mitigate the consequent risk of social awkwardness by maintaining space for face saving.

7. Provide opportunities to engage friends, family and others as spectators, but remember that giving is not the same as sharing and bear in mind that wrappings as well as gift items might be saved and shared.

We believe that these considerations might potentially be applied to a wide variety of types of gift, from traditional physical goods that can be digitally wrapped to enhance their social connectivity; to new kinds of digital goods that can be physically wrapped so as to enhance the experiential value of the gift exchange; to gift items that are themselves experiences such as museum visits. We anticipate that these could enhance a variety of everyday gifting practices such as gifting an iTunes gift card, a music playlist or buying a gift on Amazon, but might also inspire new kinds of gifting experience that combine the physical and digital in deeper ways.

Turning to researchers, we propose that our research speaks to three current threads of HCI research, shedding new light on past discussions or suggesting avenues for further investigation: 
- With respect to HCI's longstanding concern with the question of physical-digital hybridity - which has previously explored hybrid materials, artefacts and materials - we introduce the new concept of hybrid wrapping. This involves the temporary layering of physical on digital or vice versa through acts of wrapping and unwrapping so as to transform an existing experience into a new one (a gift). The original experience emerges at the end, but so does the residue from the wrapping, which captures important memories of the gift.

- With respect to HCI's recent concern with effortful interactions, we have shown a further way in which deliberately making interactions involve effort might lead to a rewarding experience. Our reflections highlight ways of making this effort pleasurable as well as visible while highlighting the need for acknowledgement and other challenges that arise from social obligation.

- HCI has also been concerned with gifting over the years, both as a lens through which to view social interactions such as the exchange of text messages and social media and also as a focus for design. We hope that our review of the literature and subsequent reflection on our portfolio has helped clarify the nature of gifting as a particular kind of social transaction, including drawing a distinction between gifting and sharing, and that this will enable others to draw on the concept in a more nuanced way.

Finally, our paper is primarily aimed at an HCI audience. However, we recognise that we have drawn on and potentially speak to literatures beyond $\mathrm{HCI}$, specifically studies of gifting from sociology and understandings of goods, products and experiences from business and marketing. We have found these to be useful perspectives to widen our understanding and encourage $\mathrm{HCI}$ researchers to further engage with these related fields in the future.

\section{ACKNOWLEDGMENTS}

The work is supported by the European Union's Horizon 2020 research and innovation programme under Grant No.: 727040 - the GIFT project.

\section{Statement of previous research}

This paper reflects across a portfolio of previously published works. While each has been published on its own, this paper is the first to offer a higher-level analysis and comparison as an integrated portfolio. This analysis then focuses on the idea of digital wrapping that we develop here, while also drawing on our previous research into gifting, as it is referenced throughout.

\section{References}

Alston, A., 2016. Beyond Immersive Theatre: Aesthetics, Politics and Productive Participation. Palgrave Macmillan.

Angus, A., Lane, G. and Roussos, G., 2014. Public Goods: Using Pervasive Computing to Inspire Grassroots Activism. IEEE Pervasive Computing Special Issue - Pervasive Data and Analytics/Citizen Science, 13(2)., 44-51, https://doi.ieeecomputersociety.org/10.1109/MPRV.2014.33.

Arthur, W. B., 2009. The nature of technology: What it is and how it evolves. Simon and Schuster.

Barden, P., Comber, R., Green, D., Jackson, D., Ladha, C., Bartindale, T., Olivier, P., 2012. Telematic dinner party. In: Proceedings of the Designing Interactive Systems Conference on - DIS'12 (p. 38). ACM Press, New York, USA. http://dx. doi.org/10.1145/2317956.2317964.

Belk, R. and Coon, G., 1993, Gift Giving as Agapic Love: An Alternative to the Exchange Paradigm Based on Dating Experiences. Journal of Consumer Research 20, no. 3. 393-417. http://www.jstor.org/stable/2489355.

Benford, S. and Gianacchi, G., 2011. Performing Mixed Reality, MIT Press.

Benford, S., Koleva, B., Quinn, A., Thorn, E.C., Glover, K., Preston, W., Hazzard, A., Rennick-Egglestone, S., Greenhalgh, C. and Mortier, R., 2017. Crafting interactive decoration. ACM Transactions on Computer-Human Interaction (TOCHI), 24(4), p.26.

Benford, S., Koleva, B., Preston, W., Angus, A., Thorn, E-C. Glover, K., 2018. Customising Hybrid Products, CHI 2018, April 21-26, 2018, Montreal, QC, Canada, ACM. 
Bradford, T. W., Grier, S. A. and Henderson, G. R., 2012. Gifts and Gifting in Online Communities, Research in Consumer Behavior, 2012, Emerald Group Publishing Limited.

Brown, B. and Sellen, A., 2006. "Sharing and Listening to Music," in Consuming Music Together: Social and Collaborative Aspects of Music Consumption Technologies, ed. Kenton O'Hara and Barry Brown, Dordrecht: Springer, 37-56.

Buechley, L. and Perner-Wilson, H. Crafting technology: Reimagining the processes, materials, and cultures of electronics, ACM Transactions on Computer-Human Interaction (TOCHI), v.19 n.3, p.1-21, October 2012 [doi> 10.1145/2362364.2362369].

Bullinger, H.J., Fähnrich, K.P. and Meiren, T., 2003. Service engineering-methodical development of new service products. International Journal of Production Economics, 85(3), pp.275-287.

Carrier, J. (1991). "Gifts, Commodities, and Social Relations: A Maussian View of Exchange”. Sociological Forum 6(1): 119-136.

Cele, O., Kim, Y.C., and Lowrey, T.,1992. Ho, Ho, Woe: Christmas Shopping for 'Difficult' People, in Advances in Consumer Research, Vol. 19, ed. John Sherry and Brian Sternthal, Provo, UT: Association for Consumer Research, 482-487.

Cheal, D.,1987. Showing them you love them: gift giving and the dialectic of intimacy. Sociological Review 35(1), 150-169.

Cheal, D., 1988. The Gift Economy. Londen: Routledge.

Clarke, J., 2007. The Four 'S's' of experience gift giving behaviour, International Journal of Hospitality Management, Volume 26, Issue 1, Pages 98-116, ISSN 0278-4319, https://doi.org/10.1016/j.ijhm.2005.10.001.

Costanza, E. and Huang, J., 2009. April. Designable visual markers. In Proceedings of the SIGCHI Conference on Human Factors in Computing Systems (pp. 1879-1888). ACM.

Davies, G., Whelan, S., Foley, A. and Walsh, M., 2010. Gifts and Gifting. International Journal of Management Reviews, 12: 413-434. doi:10.1111/j.1468-2370.2009.00271.x.

Derrida. J., 1992. Given time: I. Counterfeit money. Translated by Peggy Kamuf. Chicago: University of Chicago.

Devendorf, L. and Rosner, D. K., 2017. Beyond Hybrids: Metaphors and Margins in Design. In Proceedings of the 2017 Conference on Designing Interactive Systems (DIS '17). ACM, New York, NY, USA, 9951000. DOI: https://doi.org/10.1145/3064663.3064705.

Fosh, L., Benford, S., Reeves, S., and Koleva. B., 2014. Gifting personal interpretations in galleries. In Proceedings of the SIGCHI Conference on Human Factors in Computing System (CHI'14). ACM. 625634.

Fosh, L., Benford, S., \& Koleva, B., 2016. Supporting group coherence in a museum visit. In Proceedings of the 19th ACM Conference on Computer-Supported Cooperative Work \& Social Computing (CSCW '16) (pp. 1-12). https://doi.org/10.1145/2818048.2819970

Frohlich, D., \& Murphy, R., 2000. The memory box. Personal and Ubiquitous Computing, 4(4), 238-240.

Golsteijn, C., Hoven, E., Frohlich, D., and Sellen, A. 2014. Hybrid crafting: towards an integrated practice of crafting with physical and digital components. Personal Ubiquitous Comput. 18, 3 (March 2014), 593611. DOI=http://dx.doi.org/10.1007/s00779-013-0684-9.

Greenhalgh, C., Hazzard, A., McGrath, S. and Benford, S., 2016. October. GeoTracks: Adaptive music for everyday journeys. In Proceedings of the 24th ACM international conference on Multimedia (pp. 4246). ACM.

Grimes, A., Harper, R., 2008. Celebratory technology. In: Proceeding of the TwentySixth Annual CHI Conference on Human Factors in Computing Systems - CHI'08 (p. 467). ACM Press, New York, USA. http://dx.doi.org/10.1145/1357054. 1357130.

Hendry, J., 1995. Wrapping Culture: Politeness, Presentation, and Power in Japan and Other Societies. Oxford: Clarendon.

Ishii, H. and Ullmer, B., 1997. March. Tangible bits: towards seamless interfaces between people, bits and atoms. In Proceedings of the ACM SIGCHI Conference on Human factors in computing systems (pp. 234-241). ACM. 
Karyda, M., Rodríguez, I., \& Lucero, A., 2018. Gifting Interpretations of Personal Data. In Extended Abstracts of the 2018 CHI Conference on Human Factors in Computing Systems (pp. 1-6). New York: ACM Press. https://doi.org/10.1145/3170427.3188552.

Kelly, R. and Gooch. D., 2012. Understanding participation and opportunities for design from an online postcard sending community. In Proceedings of the Designing Interactive Systems Conference (DIS '12). ACM, 568-571.

Komter, A., 2007. Gifts and Social Relations: The Mechanisms of Reciprocity, International Sociology, 22(1), pp. 93-107. doi: 10.1177/0268580907070127.

Kotler, P., 1967. Marketing management: Analysis, planning and control. New York: Prentice Hall

Kwon, H., Jaiswal, S., Benford, S., Seah, S.A., Bennett, P., Koleva, B., and Schnädelbach, H., 2015. FugaciousFilm: Exploring Attentive Interaction with Ephemeral Material. In Proceedings of the 33rd Annual ACM Conference on Human Factors in Computing Systems (CHI '15). ACM, New York, NY, USA, 1285-1294. DOI: https://doi.org/10.1145/2702123.2702206

Kwon, H., Koleva, B., Schnädelbach, H. and Benford, S., 2017-a. It's Not Yet A Gift: Understanding Digital Gifting. In Proceedings of the 2017 ACM Conference on Computer Supported Cooperative Work and Social Computing (pp. 2372-2384). ACM.

Kwon, H., 2017-b. "From Ephemerality to Delicacy: Applying Delicacy in the Design Space of Digital Gifting". PhD Thesis. University of Nottingham. http://eprints.nottingham.ac.uk/46705/

Larsen, D. and Watson, J. J., 2001., A guide map to the terrain of gift value. Psychology \& Marketing, 18: 889-906. doi:10.1002/mar.1034

Lévi-Strauss, C., 1996. The Principle of Reciprocity, in A. Komter (ed.) The Gift: An Interdisciplinary Perspective, pp. 18-26. Amsterdam: (Orig. pub. 1949.)

Levitt, T., 1980. Marketing success through differentiation-of anything (pp. 83-91). Graduate School of Business Administration, Harvard University.

Leyshon, A., 2014. Reformatted: Code, networks, and the transformation of the music industry. Oxford University Press, USA.

Machon, J. 2013. Immersive Theatres: Intimacy and immediacy in contemporary performance. Palgrave Macmillan.

Malinowski, B., 2013. Argonauts of the Western Pacific: An Account of Native Enterprise and Adventure in the Archipelagoes of Melanesian New Guinea [1922/1994]. Routledge.

Manzini, E. and Vezzoli, C., 2003. A strategic design approach to develop sustainable product service systems: examples taken from the 'environmentally friendly innovation' Italian prize. Journal of cleaner production, 11(8), pp.851-857.

Mauss, M. The Gift: Forms and Functions of Exchange in Archaic Societies, 1925. Trans. Ian Cunnison. New York: Norton. 1967 (reprint).

McGee, K., \& Skageby, J., 2004. Gifting Technologies. First Monday, 9(12), 1-12. https://doi.org/papers3://publication/uuid/107FF3E8-B63A-4FCA-81BC-76EDD0C3959D

McGrath, M. A., Sherry, J.F. Jr., and Levy S. J., 1993. "Giving Voice to the Gift: The Use of Projective Techniques to Recover Lost Meanings," Journal of Consumer Psychology, 2 (No. 2), 171-191.

Milgram, P. and Kishino, F., 1994. A taxonomy of mixed reality visual displays. IEICE TRANSACTIONS on Information and Systems, 77(12), pp.1321-1329.

Murer, M., Aslan, I., Tscheligi, M., 2013. LOLLio: Exploring taste as playful modality. Proceedings of the 7th International Conference on Tangible, Embedded and Embodied Interaction-TEI '13, ACM Press, New York, NY, USA, pp. 299-302. doi:10.1145/2460625.2460675.

Pandya, A. and Venkatesh, A., 1992."Symbolic Communication Among Consumers in Self-Consumption and Gift Giving: a Semiotic Approach", in NA - Advances in Consumer Research Volume 19, eds. John F. Sherry, Jr. and Brian Sternthal, Provo, UT : Association for Consumer Research, Pages: 147-154.

Paolacci, G., Straeter, L. M., \& Hooge, I. E. De., 2015. Give me your self: Gifts are liked more when they match the giver's characteristics. Journal of Consumer Psychology, 25(3), 487-494. https://doi.org/10.1016/j.jcps.2015.01.006 
Pine, B.J. and Gilmore, J.H., 1998. Welcome to the experience economy. Harvard business review, 76, pp.97105.

Robben, H. S. J., and Verhallen, T. M. M., 1994. Behavioral costs as determinants of cost perception and preference formation for gifts to receive and gifts to give. Journal of Economic Psychology, 15, 333 350 .

Ruffle, B., 1999. Gift Giving with Emotions, Journal of Economic Behavior and Organization, 39 399-420.

Salovaara, A., 2008. Struggling with gift-giving obligations: when mobile messages are too laborious to reciprocate. In Proceedings of the 22nd British HCI Group Annual Conference on People and Computers: Culture, Creativity, Interaction-Volume 2 (pp. 83-86).

Schwarz, Ori., 2010. "On Friendship, Boobs and the Logic of the Catalogue: Online Self-Portraits as a Means for the Exchange of Capital." Convergence, 16 (2), 163-83.

Sharon K. Banks, 1979. "Gift-Giving: A Review and an Interactive Paradigm," in Advances in Consumer Research, Vol. 6, ed. William Wilkie, Ann Arbor, MI: Association for Consumer Research, 319-324.

Sherry, J.F., 1983. Gift giving in anthropological perspective. Journal of Consumer Research 10 (2), 157168.

Sherry, J.F., Jr, McGrath, M.A., and Levy S.J., 1993. "The Dark Side of the Gift," Journal of Business Research, 28 (November), 225-244.

Sherry, J.F., Jr, McGrath, M.A., and Levy S.J., 1992. "The Disposition of the Gift and Many Unhappy Returns," Journal of Retailing, 68 (No. 1), 40-65.

Skågeby, J., 2010. Gift-giving as a conceptual framework: Framing social behavior in online networks. Journal of Information Technology, 25(2), 170-177. https://doi.org/10.1057/jit.2010.5

Smith, L., Maull, R. and CL Ng, I., 2014. Servitization and operations management: a service dominant-logic approach. International Journal of Operations \& Production Management, 34(2), pp.242-269.

Spence, J., Hazzard, A., McGrath, S., Greenhalgh, C., and Benford, S., 2017. "The Rough Mile: Testing a Framework of Immersive Practice". Proceedings of the 2017 Conference on Designing Interactive Systems. ACM Press, 877-888.

Spence, J., 2019. Inalienability: Understanding Digital Gifts. In Proceedings of the 2019 CHI Conference on Human Factors in Computing Systems (p. 657). ACM.

Spence, J., Bedwell, B., Coleman, M., Benford, S., Koleva, B.N., Adams, M., Row Farr, J., Tandavanitj, N. and Løvlie, A.S., 2019. Seeing with New Eyes: Designing for In-the-Wild Museum Gifting. In Proceedings of the 2019 CHI Conference on Human Factors in Computing Systems (p. 5). ACM.

Sunwolf, J. D., 2006. The Shadow Side of Social GiftGiving: Miscommunication and Failed Gifts, Communication Research Trends, Centre for the Study of Communication and Culture, Vol. 25(3): 144.

Taylor, A. and Harper, R., 2002. Age-old practices in the 'new world': a study of gift-giving between teenage mobile phone users. In Proceedings of the SIGCHI Conference on Human Factors in Computing Systems (CHI '02). ACM, 439-446.

Tukker, A. and Tischner, U., 2006. New business for old Europe. Product-service development, competitiveness and sustainability. Greenleaf, Sheffield, 192.

Vandermerwe, S. and Rada, J., 1988. Servitization of business: adding value by adding services. European management journal, 6(4), pp.314-324.

Waldman, M., 2003. Durable goods theory for real world markets. The Journal of Economic Perspectives, 17(1), pp.131-154.

Watts, J. K. M., \& Shmargad, Y., 2015. Social Visibility and the Gifting of Digital Goods. In COSN '15 Proceedings of the 2015 ACM on Conference on Online Social Networks (pp. 49-58). https://doi.org/10.2139/ssrn.2679671.

Wei, J., Ma, X., and Zhao, S., 2014. Food messaging: using edible medium for social messaging. In Proceedings of the SIGCHI Conference on Human Factors in Computing Systems (CHI '14). ACM, 2873-2882.

Weiner, A. B., 1992. Inalienable Possessions: The Paradox of Keeping-While-Giving. University of California Press. 
Weiser, M., 1991. The computer for the 21st Century, Scientific American, vol. 265 (3), pp. 94--104.

Wooten, D. B. "Qualitative Steps toward an Expanded Model of Anxiety in Gift-Giving." Journal of Consumer Research 27, no. 1 (2000): 84-95. doi:10.1086/314310.

Yang, J., Ackerman, M. S., and Adamic, L. A. 2011. Virtual gifts and guanxi: supporting social exchange in a chinese online community. In Proceedings of the ACM 2011 conference on Computer supported cooperative work (CSCW '11). ACM, 45-54. 